\title{
Microcirculation of the Rat Pancreas, with Special Reference to the Insulo-Acinar Portal and Insulo-Venous Drainage Systems: A Further Scanning Electron Microscope Study of Corrosion Casts*
}

\author{
Takuro MURakami ${ }^{1}$ and Tsuneo FuJita ${ }^{2}$ \\ Departments of Anatomy, Okayama University School of Medicine, Okayama ${ }^{1}$, and Niigata University School of Medicine, \\ Niigata ${ }^{2}$, Japan
}

Received August 12, 1992

\begin{abstract}
Summary. Microcirculation in rat pancreas was studied by scanning electron microscopy of resin vascular casts and by light microscopy of India ink-injected and sectioned tissue samples. In the scanning survey of the casts, islets larger than $30 \mu \mathrm{m}$ in diameter counted no less than 400 in the adult rat pancreas. They were located either in the exocrine lobules (intralobular islets, counting 210 or more), or in the interlobular tissue spaces and along the secretory ducts (extralobular islets, 190 or more).

Every islet received arterial blood via one or more proper arterioles. These afferent vessels first divided in the peripheral zone of the islet consisting of $A$ and $D$ cells and later extended deeper to form a capillary network in the islet core consisting of $B$ cells. Blood originating from this capillary network left the islet via efferent vessels. This microvascular pattern may favor the regulation by $A$ and $D$ cells over the secretory activity of $B$ cells.
\end{abstract}

The intralobular islets gave their efferent vessels to the capillary bed of the exocrine tissue of the lobule, thus forming an insulo-acinar portal system. When the lobule was relatively small in size, superfluent blood was led directly to veins via insulo-venous drainage vessels. The intralobular islets sometimes issued one or more long translobular portal vessels reaching adjacent lobules.

The extralobular islets issued either insulovenous vessels draining to interlobular veins, or extralobular insulo-acinar portal vessels supplying adjacent lobules.

Early light microscopic studies in the horse, rabbit and mouse of dye-injected tissue samples suggested that the efferent vessels of the endocrine pancreas (islets of Langerhans) were continuous with the capillaries of the exocrine pancreas (exocrine acini or lobules) (BECK and BERG, 1931; WHARTON, 1932; THIEL, 1954).

Recent light microscopic studies in the monkey, horse, dog, rabbit and rat of India ink-injected tissues or scanning electron microscopic studies of corrosion casts have confirmed that the capillaries of the islets emit efferent vessels to the capillary network in the exocrine tissue. This microcirculatory pattern has been referred to as the insulo-acinar portal system (Fujita, 1973; Fujita and Watanabe, 1973; Fujita and Murakami, 1973; Fujita et al., 1976; Ohtani and FUJITA, 1981; OHTANI et al., 1986). Recently, we demonstrated the occurrence of a typical portal system in human pancreas (MURAKAMI et al., 1992). However, some authors have contended that the efferent vessels of the islets in the rat mainly drained into veins, their drainage into the lobular capillaries via portal vessels being minor (BONNER-WEIR and ORCI, 1982). We believe that this controversy is mainly due to a peculiarly complex pattern of microcirculation in the pancreas of this popular laboratory animal, namely, the rat. A precise observation of the pancreatic blood vessels in this species thus seems necessary to draw a general view concerning the microcirculation connecting the endocrine and exocrine portions of the mammalian pancreas.

The present study, therefore, reinvestigates the blood vascular bed of the rat pancreas by scanning electron microscopy of corrosion casts and by light micro-

*This work was supported in part by a grant from the Ministry of Education, Science and Culture, Japan. 


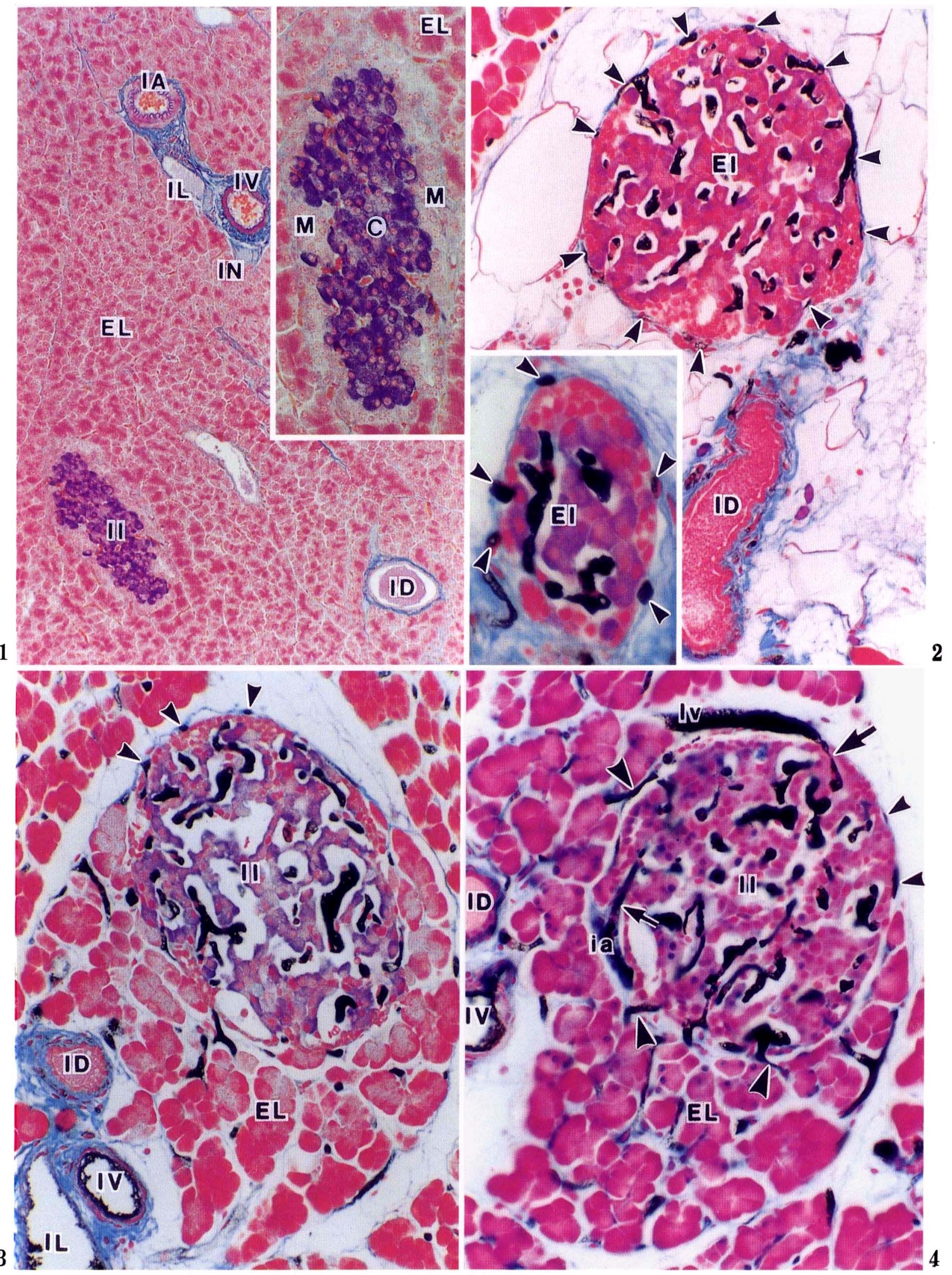

Figs. 1-4. Legends on the opposite page. 
Table 1. Abbreviations used in figures.

$C \quad$ B cell core of the islet

$M \quad$ A-D cell mantle of the islet

$C D$ Common bile duct or its vascular plexus

$C P$ Central lobe of the pancreas or its vascular bed

EI Extralobular (interlobular or periductal) islet or its vascular plexus

EL Exocrine lobule or its vascular plexus

$G N$ Ganglion of nerve or its vascular plexus

$H P$ Hepatic portal vein

IA Interlobular artery or its branch

ID Interlobular secretory duct or its vascular plexus (periductal plexus)

II Intralobular endocrine islet or its vascular plexus

IL Interlobular lymphatic vessel or its vascular plexus

IN Interlobular nerve bundle or its vascular plexus

$I V$ Interlobular vein or its branch

$K I$ Kidney or its vascular bed

$L A$ Lobular artery

$L D$ Lobular duct or its vascular plexus

$L I \quad$ Liver or its vascular bed

$L N$ Solitary lymph node or its vascular plexus

$L P$ Left lobe of the pancreas or its vascular bed

$L V$ Lobular vein
$P A \quad$ Lobular penetrating artery

$P S$ Portal spiral of the hepatic portal vein

$P V$ Lobular penetrating vein

$R P$ Right lobe of the pancreas or its vascular bed

$S P$ Spleen or its vascular bed

a Arterial branch

$v \quad$ Venous branch

ca Capsular afferent rootlet of the islet

ep Extralobular insulo-acinar portal vessel

ia Afferent vessel of the islet

ic Capillary-like or thin insulo-venous efferent vessel

ie Efferent rootlet of the islet

ip Intralobular insulo-acinar portal vessel

iv Insulo-venous efferent vessel

la Branch (acinar artery) of the lobular artery directly continuous with the lobular capillary plexus

lv Branch of the lobular vein originating in the lobular capillary plexus

sc Surface capillary meshwork (capsular meshwork) of the islet or its capillaries

tp Translobular insulo-acinar portal vessel

$v p$ Insulo-acinar portal branch of the insulo-venous efferent vessel

Fig. 1. Light micrographs of a section of adult rat pancreas, stained with Gomori's aldehyde fuchsin and Masson-Goldner's trichome (without Weigert's hematoxylin). The pancreas basically comprises exocine lobules $(E L)$ and endocine islets $(I I)$. In the loose connective tissue (stained green) bordering the lobules are shown an interlobular duct $(I D)$, nerve $(I N)$, lymphatic $(I L)$, artery $(I A)$ and vein $(I V)$. Inset shows a closer view of the islet. Note that in the rat islet $(I I)$, the core $(C)$ is mainly occupied by B cells reactive with fuchsin and the periphery comprises the A-D cell mantle $(M) . \times 75$, Inset: $\times 170$

Fig. 2. A section of India ink-injected rat pancreas treated with aldehyde fuchsin-trichrome staining (without hematoxylin). Note that the extralobular or interlobular islet $(E I)$ is provided with fine capillaries in and beneath the capsule of the islet (capsular capillaries; arrowheads). Inset shows another small extralobular islet $(E I)$ with capsular capillaries (arrowheads). For other abbreviations, see Table $1 . \times 200$, Inset: $\times 300$

Fig. 3. A section of India ink-injected rat pancreas stained with aldehyde fuchsin-trichrome (without homatoxylin). An islet $(I I)$ is seen in an exocrine lobule $(E L)$. Arrowheads indicate the capsular capillaries of the islet. For other abbreviations, see Table $1 . \times 200$

Fig. 4. An intralobular islet $(I I)$ observed in a section stained with cationic iron colloid ( $\mathrm{pH} 2.0)$. Note that the islet receives at its superficial aspect an afferent rootlet (small arrow), and issues fine vessels running into the exocrine lobule $(E L)$ (large arrowheads) or draining into the lobular venous branch (lv; large arrow). Small arrowheads indicate capsular capillaries of the islet. For other abbreviations, see Table $1 . \times 200$ 
scopy of India ink-injected tissue samples, and demonstrates the details of the insulo-acinar portal and insulo-venous systems in this animal. Findings on the lobular, ductal and other microvasculatures in the pancreas are also included.

\section{MATERIALS AND METHODS}

A low viscosity or semi-polymerized methacrylate mixture (Murakami, 1971; Murakami et al, 1973) was diluted with $30-40 \%$ monomeric methyl methacrylate. This diluted resin mixture showed a viscosity similar to that of blood.

Adult male Wistar rats weighing $300-400 \mathrm{~g}$ were anesthetized with ethyl ether, infused thoroughly via the thoracic aorta with a physiological saline solution $(30-40 \mathrm{ml})$, and then with a diluted resin mixture (20$30 \mathrm{ml}$, see above) or India ink (20-30 ml) under an injection pressure of $30-40 \mathrm{mmHg}$ until the inferior
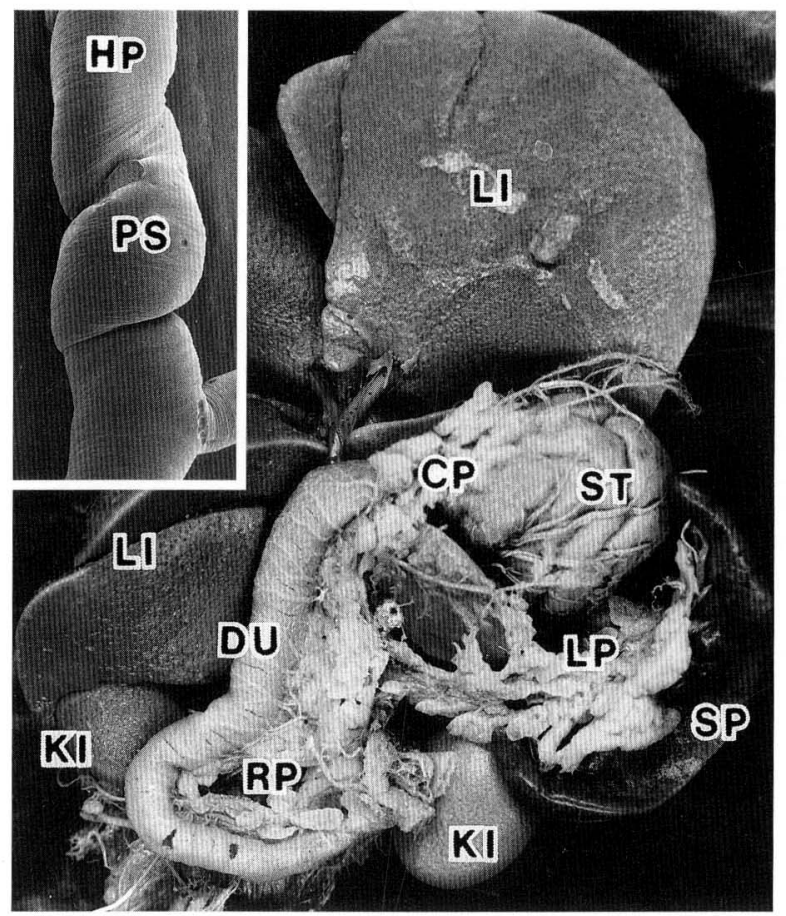

Fig. 5. Photograph of thoroughly replicated upper abdominal organs of an adult rat. Note that the blood vascular bed of the pancreas (CP central lobe; $L P$ left lobe; $R P$ right lobe) is sufficiently reproduced together with other abdominal organs. Inset shows a scanning electron micrograph of the replicated spiral $(P S)$ of the hepatic portal vein $(H P)$. For other abbreviations, see Table 1. $\times 1.3$, Inset: $\times 10$

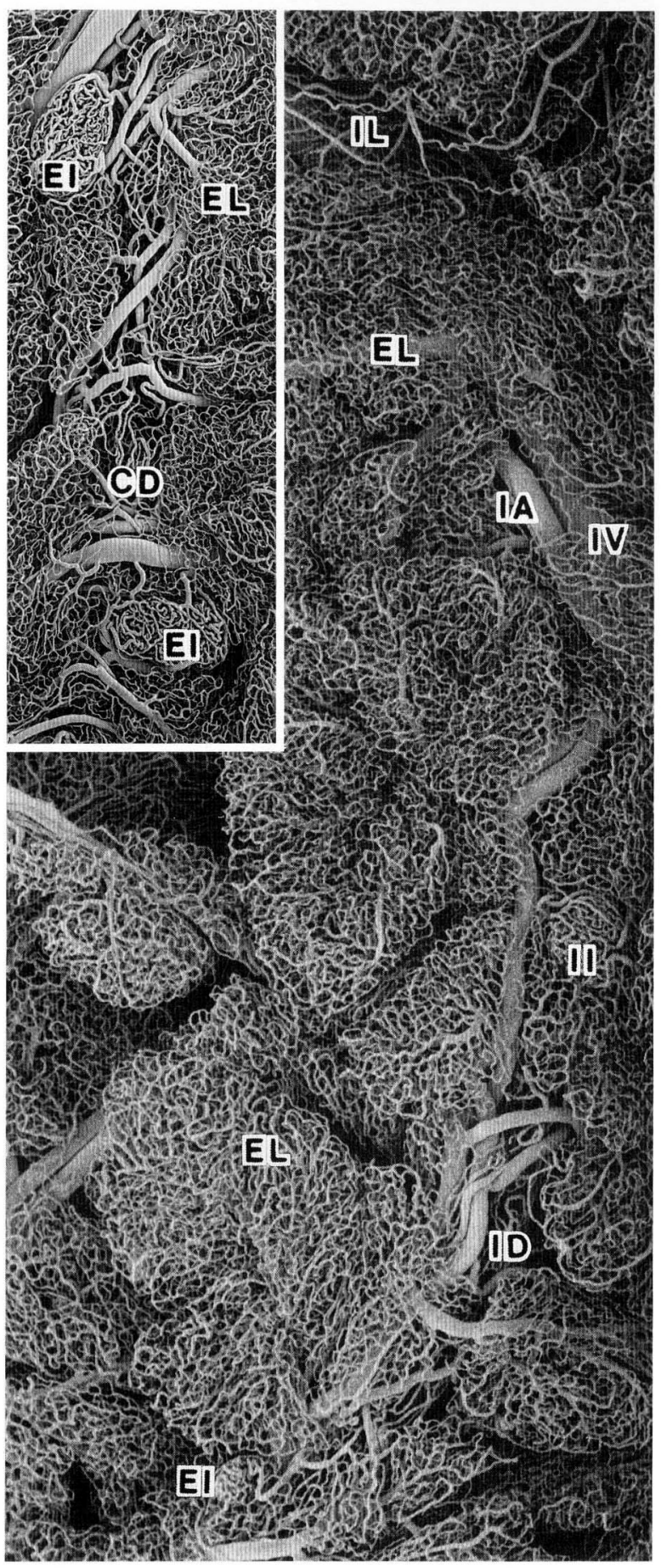

Fig. 6. Survey scanning view of the blood vascular cast of the adult rat pancreas (a part of the right lobe shown in Figure 5). Note that the pancreatic blood vascular bed is satisfactorily reproduced. Inset shows two extralobular (periductal) islets $(E I)$ closely associated with the (periducted plexus of) common bile duct $(C D)$. For other abbreviations, see Table $1 . \times 35$, Inset: $\times 25$ 
vena cava was filled with the injected resin or ink. Some of the anesthetized rats received neither saline nor resin infusion and served as control animals.

The resin-injected bodies were placed for about $6 \mathrm{~h}$ or longer in a hot water bath $\left(60^{\circ} \mathrm{C}\right)$, corroded overnight or longer in a hot $5-10 \% \mathrm{NaOH}$ solution $\left(60^{\circ} \mathrm{C}\right)$, and washed overnight or longer in running tap water. The blood vascular casts of the pancreata thus prepared were isolated together with their connecting vessels and other upper abdominal organs, air-dried, and dissected with sharpened forceps or needles under a binocular microscope (SMZ-10, Nikon). The specimens were then exposed to evaporized osmium tetroxide (MURAKAMI et al., 1973), sputter-coated with gold in a vacuum evaporator, and observed with a scanning electron microscope (HHS-2R or S-2300, Hitachi) using an acceleration voltage of $5 \mathrm{kV}$.

The pancreas was excised from the India ink-injected and control animals, and cut into blocks. These blocks were fixed overnight or longer in Bouin's solution, embedded in paraffin, cut into sections, stained with Gomori's aldehyde fuchsin and MassonGoldner's trichrome (without Weigert's hematoxylin) or with cationic iron colloid $(\mathrm{pH} 1.5-2.0)$ and nuclear fast red (MURAKAMI et al., 1986), and observed with a light microscope (BH-2, Olympus).

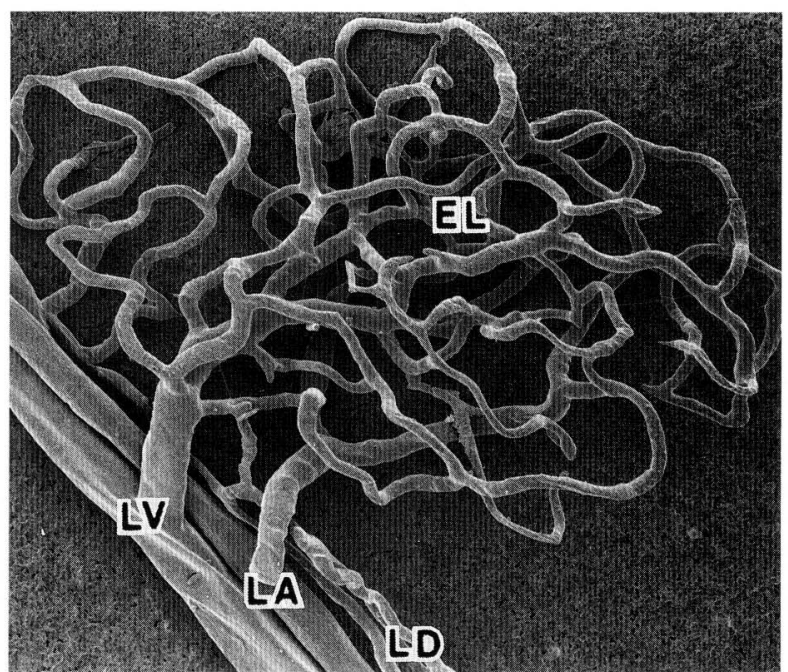

Fig. 7. Isolated blood vascular plexuses of a peripheral lobule $(E L)$ and its duct $(L D)$. Note that this lobular vascular plexus forms an independent system. For other abbreviations, see Table $1 . \times 260$

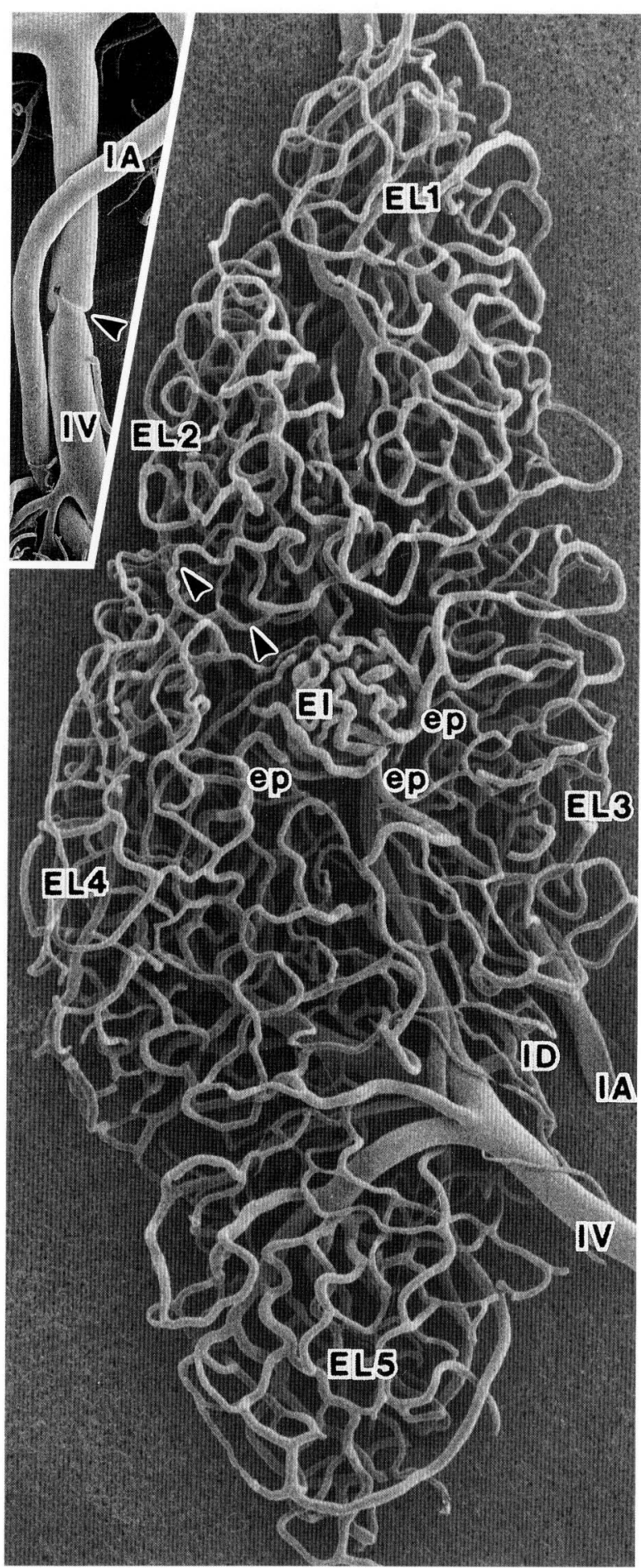

Fig. 8. A sublobar unit composed of five vascular lobules (EL1-EL5). Note that this unit contains an extralobular islet $(E I)$ which emits extralobular insulo-acinar portal vessels (ep) draining into the EL3 and EL4 lobules. Arrowheads indicate the translobular capillaries between the EL2 and EL4 lobules. Inset shows a Vshaped impression of venous valve. For other abbreviations, see Table $1 . \times 145$, Inset: $\times 35$ 


\section{RESULTS}

\section{Light microscopy of tissue samples}

Freshly fixed pancreata from control animals, i.e., receiving neither saline nor India ink infusion, reacted well to the aldehyde fuchsin and cationic iron colloid stainings; the B cell core of the islet was well contrasted with fuchsin (Fig. 1, Inset).

The saline- and India ink-injected pancreata were more or less degenerative, reacting less distinctly to the fuchsin and colloid stainings (Figs. 2-4). Injection naturally was essential to demonstrate blood vessels; it further served to visualize the lobulation of the exocrine pancreas since it made the pancreas edematous, widening tissue spaces (Figs. 3, 4).

Light microscopy of tissue samples thus confirmed that the rat pancreas is a complicated organ which basically comprises exocrine lobules, secretory ducts and endocrine islets (Figs. 1-4). The exocrine lobules were bound together by a loose connective tissue stroma through which ran the interlobular ducts, arteries, veins, nerves and lymphatics (Figs. 1, 3, 4).

The endocrine islets were located either in the lobules as the intralobular islets (Figs. 3, 4), or in the interlobular tissue spaces as the extralobular (interlobular) islets (Fig. 2, Inset).

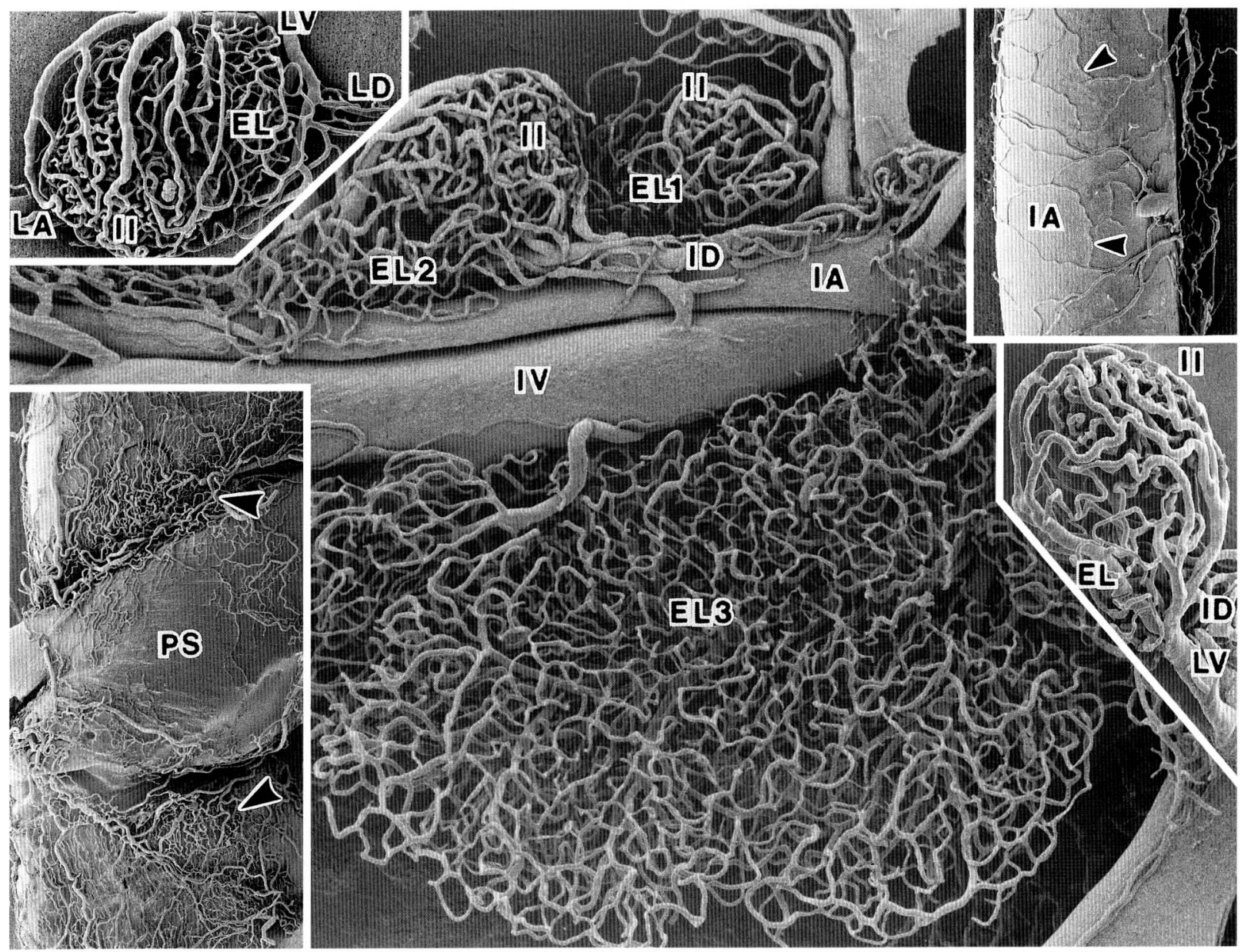

Fig. 9. Three vascular lobules (EL1-EL3) exposed by dissection. Note that the periductal lobules (EL1, EL2) are smaller than the peripheral lobule (EL3), and each contains an islet $(I I)$. Left-upper Inset shows a lobule $(E L)$ containing an islet $(I I)$ (see text). Left-lower Inset shows well-developed vasa venosum (large arrowheads) surrounding the portal spiral (PS). Right-upper Inset shows vasa arteriosum (small arrowheads) surrounding a thick interlobular artery $(I A)$. Right-lower Inset shows a small lobule $(E L)$, which is largely occupied by an apical intralobular islet $(I I)$. For other abbreviations, see Table $1 . \times 70$. left-upper Inset: $\times 60$, left-lower Inset: $\times 40$, right-upper Inset: $\times 35$, right-lower Inset: $\times 120$ 
The exocrine lobules contained fine capillaries (lobular capillaries) winding among individual acini (Figs. 3, 4), and those surrounding the interlobular ducts in their peri-epithelial layer (Fig. 2). The interlobular tissue stroma contained some fine capillaries (interlobular capillaries). Large interlobular arteries, veins or lymphatics were surrounded by their proper capillary plexuses (vasa arteriosum, venosum and lymphaticum). Thick nerves contained many capillaries (vasa nervosum). However, middle-sized or thinner interlobular arteries, veins, lymphatics and nerves were provided with few capillaries.

The endocrine islets, regardless of type, contained a marked sinusoidal capillary plexus (parenchymal

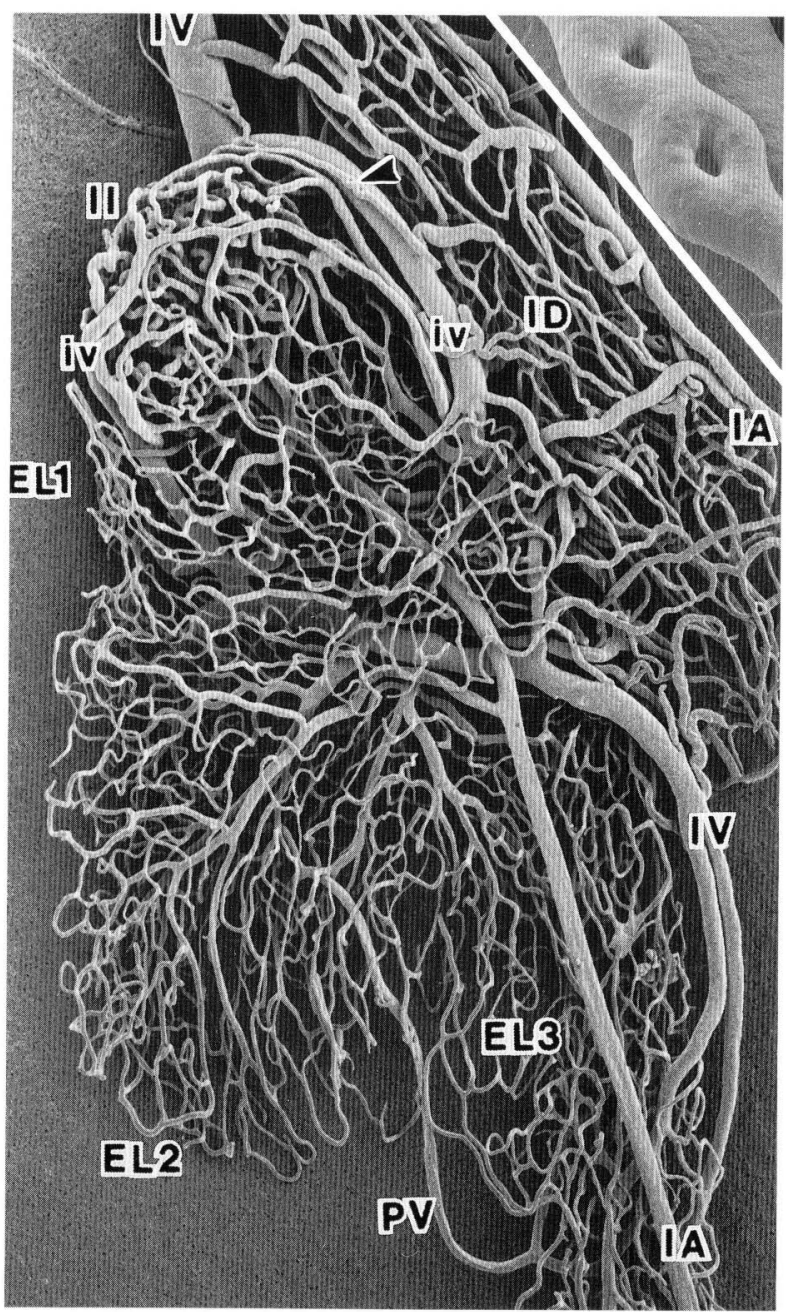

Fig. 10. Three vascular lobules (EL1-EL3) closely associated with an interlobular periductal plexus (ID). Note that the islet $(I I)$ in the ELI lobule issues a long insulovenous vessel which shows loop-like divisions (arrowhead). Inset shows a closer view of the loops. $\times 70$, Inset: $\times 680$ plexus) in their B cell core (Figs. 2-4). The islets were further provided with an additional meshwork of fine capillaries (surface or capsular meshwork) in or beneath the capsule of the islets (Fig. 2, Inset). These capsular capillaries were not always clear in the intralobular islets (Figs. 3, 4).

Each islet possessed proper afferent and efferent vessels. Small islets received one or two afferent vessels and issued three to five efferent vessels, whereas medium- or large-sized islets received two or more afferent vessels and issued six or more efferent vessels. The afferent vessels of the extralobular islets arose from the interlobular arteries or their branches, while those of the intralobular islets arose from the lobular arteries or their branches.

The islets, again regardless of type, received the afferent vessels at the A-D cell mantle or between this mantle and B cell core; these afferent vessels divided in the mantle or between the mantle and core into a few or several afferent rootlets and continued

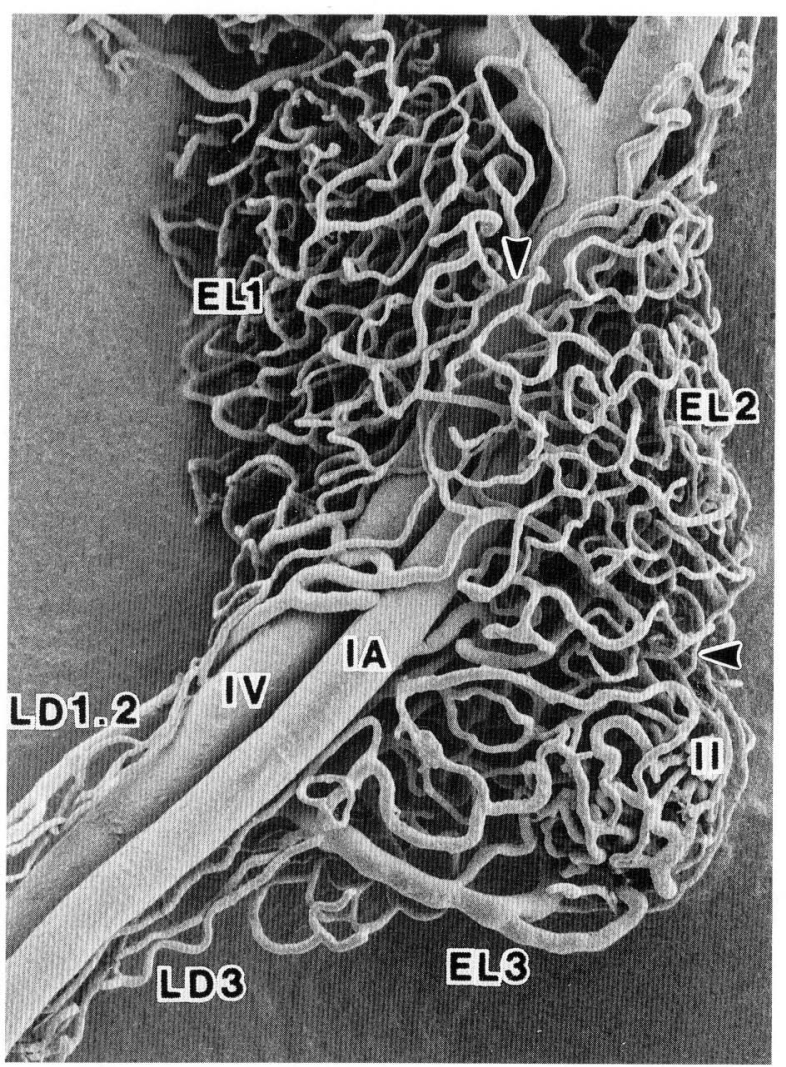

Fig. 11. Three peripheral lobules (EL1-EL3). Note that the LD3 periductal plexus of the EL3 lobule containing an islet $(I I)$ is thicker than the $L D 1.2$ periductal plexus of the EL1 and EL2 lobules containing no islet. Arrowhead indicates a translobular capillary. For other abbreviations, see Table $1 . \times 125$ 


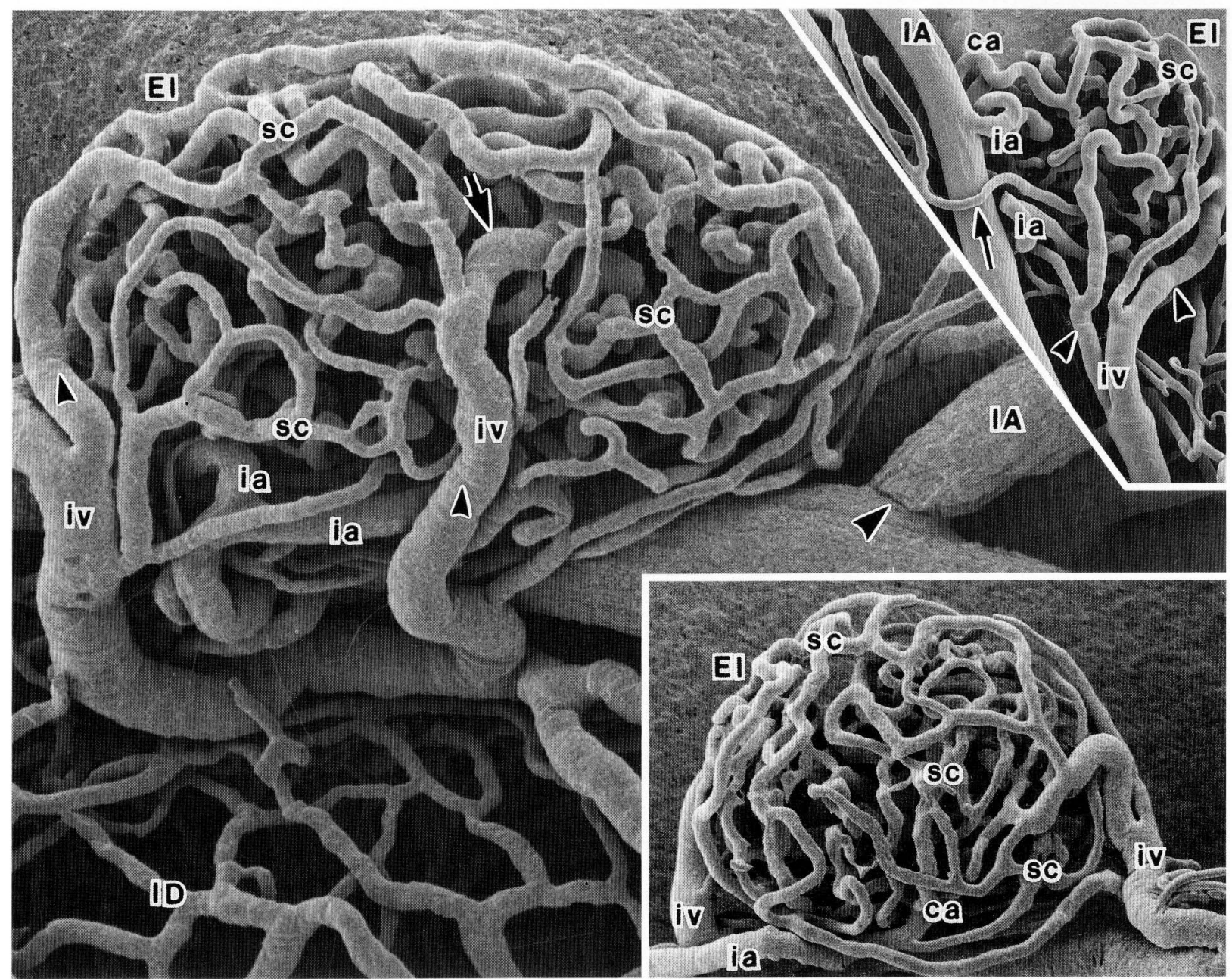

Fig. 12. An extralobular (periductal) islet (EI) closely associated with the upper main periductal plexus (ID). Note that the islet has a fine capillary (capsular) meshwork $(s c)$ on its surface, and issues a thick efferent rootlet from its deep aspect (large arrow). Small arrowheads indicate vascular contractions imprinted in the insulovenous drainage vessels $(i v)$. Large arrowhead indicates a sharp ring-like constriction imprinted at the orgin of an interlobular artery $(I A)$. Upper Inset shows a heterotopic islet $(E I)$, the capsular meshwork $(s c)$ of which receives an fairy independent arterial branch $(c a)$; small arrow indicates a rare insular vessel draining into interlobular capillaries; arrowheads indicate contractions of an insulo-venous efferent vessel ( $\mathrm{iv}$ ). Lower Inset shows another example of a periductal islet $(E I)$, the capsular meshwork $(s c)$ of which directly receives an arterial branch $(c a)$. For other abbreviations, see Table $1 . \times 370$, upper Inset: $\times 215$, lower Inset: $\times 210$

into the parenchymal plexus of sinusoidal capillaries in the B cell core (Fig. 4). The efferent vessels arose from this parenchymal plexus or from the surface meshwork of fine capillaries. The efferent vessels from the intralobular islets continued either into the lobular capillaries or into the venous branches in the lobules (Figs. 3, 4), whereas those from the extralobular islets drained into the venous branches in the interlobular spaces or along the secretory ducts.

\section{Scanning electron microscopy of vascular casts}

Thorough infusion of a low viscosity methacrylate mixture through the thoracia aorta produced satisfactory blood vascular casts of the abdominal organs (Fig. 5). The casts sufficiently reproduced the vascular plexuses of the islets, lobules, ducts and other pancreatic tissue elements (Fig. 6), and allowed precise analysis of those microvascular components with 
the binocular light and scanning electron microscopes (Figs. 6-28). The findings thus obtained are described below and schematically diagrammed in Figure 29.

\section{Pancreatic lobes, their arteries and veins}

The rat pancreas or its blood vascular bed consisted of the left (splenic), central and right (duodenal) lobes (Fig. 5). These lobes received their arterial branches (lobar arteries) from the splenic, pancreatico-duodenal and other arteries originating in the celiac or superior mesenteric artery, and emitted their venous branches (lobar veins) draining through the splenic, pancreatico-duodenal and other veins into the portal vein.

A deep, screw-like constriction was constantly imprinted in the portal vein at a level between the liver hilus and the splenic vein (Figs. 5 Inset. 9 leftlower Inset).

\section{Interlobular arteries and veins, and their branches}

The lobar arteries and veins branched into the interlobular arteries and veins, respectively. These arteries and veins usually ran in the same interlobular spaces, though they frequently ran in different spaces. In each lobe, many anastomoses were formed between the interlobular arteries and between the interlobular veins. However, no arterio-venous anastomosis was noted in any segment of the pancreas.

The interlobular arteries and veins divided in the interlobular spaces, and gave rise to the lobular, periductal and proper interlobular arteries and veins, respectively. The lobular arteries and veins supplied the capillary plexuses of the exocrine lobules (lobular capillary plexuses); the periductal ones supplied the capillary plexuses of secretory ducts, including the common bile duct (periductal capillary plexuses); the proper interlobular ones supplied the capillary plexuses of interlobular tissue structures (vasa arteriosum, vasa venosum, vasa nervosum, vasa lymphaticum and a proper interlobular capillary plexus).

A deep and sharply delineated ring-like constriction was sometimes noted at the orgins of both the interlobular artery and its branch (Figs. 12, 24). A sharply delineated $\mathrm{V}$-shaped constriction was rarely imprinted in the interlobular vein (Fig. 8 Inset). Multiple, sharp constrictions were occasionally observed in the interlobular vessels, especially the veins or their branches (Fig. 18).

\section{Interlobular vascular plexuses}

The vasa arteriosum and venosum were reproduced

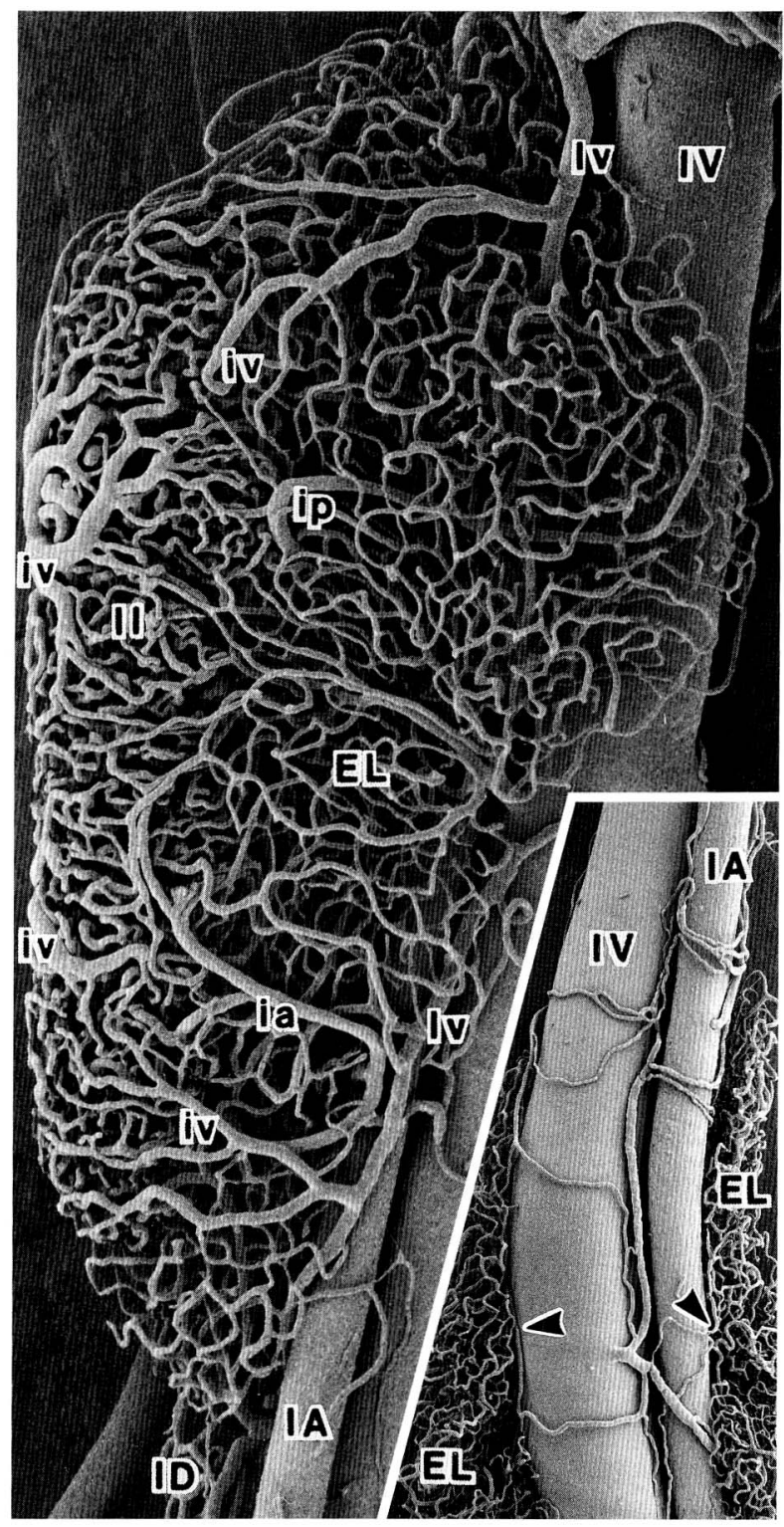

Fig. 13. A large intralobular (apical intralobular) islet $(I I)$ in a large lobule $(E L)$. A well-developed intralobular insulo-acinar portal vessel (ip) is seen. Inset shows some fine connections (arrowheads) between interlobular and lobular vessels. For other abbrevitions, see Table 1. $\times 90$, Inset: $\times 45$

as fine capillary plexuses around the interlobular arteries and veins; the vasa venosum were denser in meshwork than the vasa arteriosum (Fig. 9 rightupper Inset). Typical vasa venosum were observed around the v. portae hepatis showing screw-like constrictions (Fig. 9 left-lower Inset).

The vasa nervosum were identified as a strand of fine capillary network (Fig. 14 Inset). The capillary 


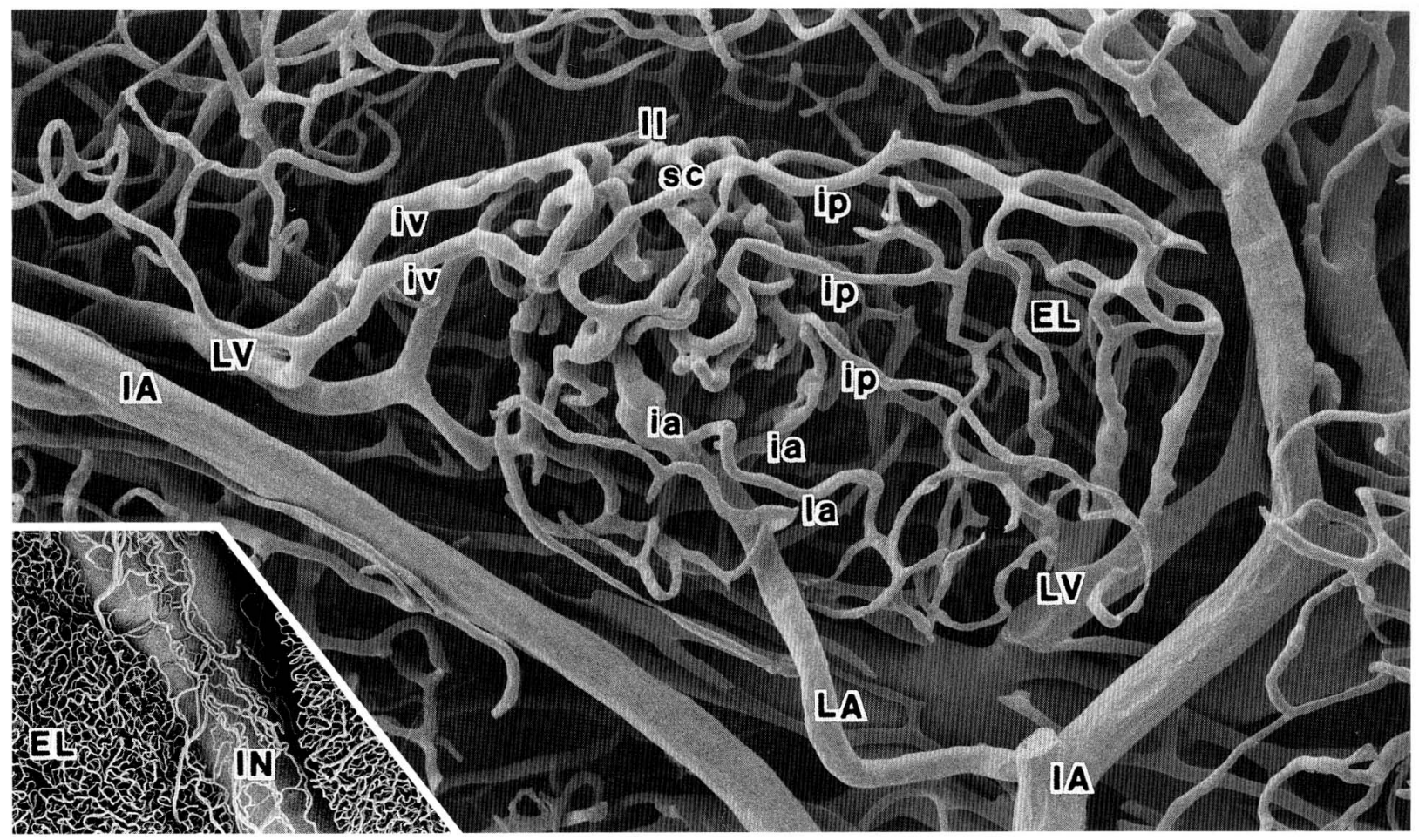

Fig. 14. A periductal lobule $(E L)$ containing a basal intralobular islet $(I I)$. Note that the islet issues three marked intralobular insulo-acinar portal vessels (ip) which form the lobular capillary plexus $(E L)$ together with a lobular (acinar) branch ( $l a)$ of the lobular artery $(L A)$. The islet, on the other hand, issues insulo-venous vessels (iv) directly draining into the lobular vein $(L V)$. Inset shows the capillary plexus of a nerve bundle $(I N)$. For other abbreviations, see Table $1 . \times 280$, Inset: $\times 40$

network supplying a nerve ganglion was somewhat conglomerated, and was provided with the proper afferent and efferent vessels (Fig. 18 upper Inset).

The vasa lymphaticum were noted as a coarse network of fine capillaries (Fig. 6). The vascular plexuses of the solitary lymphnodes, which were usually observed in the juxta-splenic segments of the left lobe, consisted of outer fine capillaries and inner venous vessels (Fig. 16 Inset). These venous vessels were characterized by their irregular surface or highly endothelial nature.

The proper interlobular capillary plexus was very coarse in meshwork (Fig. 13 Inset), and was closely associated with the vasa vasorum, nervosum and lymphaticum and also with the periductal plexus. The interlobular capillaries frequently communicated with the lobular plexuses (Fig. 13 Inset).

\section{Periductal vascular plexus}

The rat pancreas issued the upper and lower main secretory ducts. The upper main duct originated in the left and central lobes and opened into the com- mon bile duct at the level of the splenic artery or vein. The duct of the central lobe was sometimes independent, opening in isolation into the common duct at a similar level. The lower main duct originated in the right lobe and opened into the common duct near the lower end of the common duct.

The vascular plexus surrounding the secretory duct or common bile duct formed a tubular basket. The interlobular periductal plexus usually ran along the interlobular artery and vein. The plexuses of the common bile and main pancreatic ducts were accompanied by two or more interlobular arteries and veins. The plexus of either duct consisted of an inner and an outer layer; the inner layer was characterized by a dense meshwork of fine capillaries (Fig. 12), and the outer layer by a coarse meshwork of venules or veins which collected the inner capillaries. In the outer layer, periductal arteries also formed a meshwork by making many anastomoses, and then supplied the inner plexus.

As the ductal plexus was followed peripherally, the two layers became unclear. A smaller sized plexus thus comprised a single-layered network, in which 


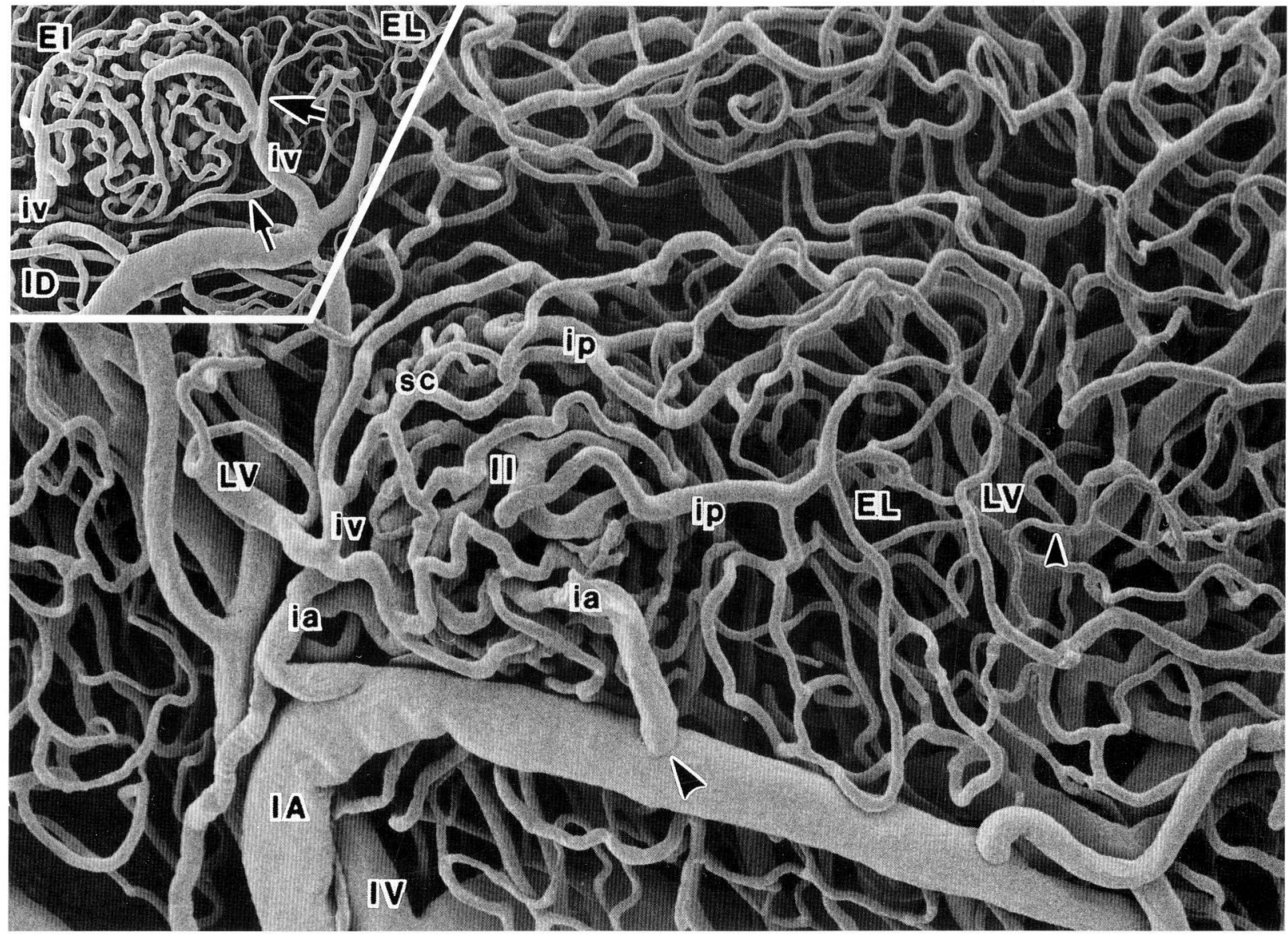

Fig. 15. A periductal lobule $(E L)$ containing a basal intralobular islet $(I I)$. This lobule receives no direct arterial branch, and therefore its capillary bed is totally supplied by the intralobular insulo-acinar portal vessels (ip). Large arrowhead indicates a constriction at the origin of an insulo-afferent vessel (ia). Small arrowhead indicates translobular capillary. Inset shows periductal islet $(E I)$, an insulo-venous drainage $(i v)$ which receives a venous branch (large arrow) from the adjacent lobule $(E L)$ and an interlobular capillary (small arrow). For other abbreviations, see Table $1 . \times 270$, Inset: $\times 110$

capillaries, arteries and veins were intermingled (Figs. 10, 16, 23). The terminal periductal plexus supplying the lobular duct consisted of a single or a few capillaries which were derived from either the periductal or intralobular arterioles and drained into either the periductal or intralobular venules (Figs. 7, 9 left-upper Inset, 11, 18).

There was a general tendency for the terminal periductal plexus in an exocrine lobule containing an endocrine islet to be considerably thicker than that in a lobule containing no islet (Figs. 9 left-upper Inset, 11, 18).

\section{Vascular plexuses of the exocrine lobules}

The lobular artery and vein usually ran along the terminal periductal plexus, and entered the lobule at or near its base (Fig. 7). On occasion, the vessels and plexus ran apart from each other (Fig. 9 left-upper Inset). The lobule frequently received one or more additional lobular arteries and also emitted one or more additional lobular veins (Fig. 22). Rarely, one or more branches of the lobular artery or vein emerged from the lobule to supply an adjacent lobule, extralobular islet (see below) or periductal plexus; such vessels may be called lobular penetrating arteries or veins (Fig. 24 lower Inset).

The lobular arteries and veins, including the additional ones, divided into finer vessels (intralobular or acinar arteries and veins), and continued into the lobular capillaries which formed a homogeneous capillary plexus (Figs. 7-11). Veno-venous anastomoses were occasionally noted between the intralobular veins. Arterio-arterial anastomoses were rather rare 


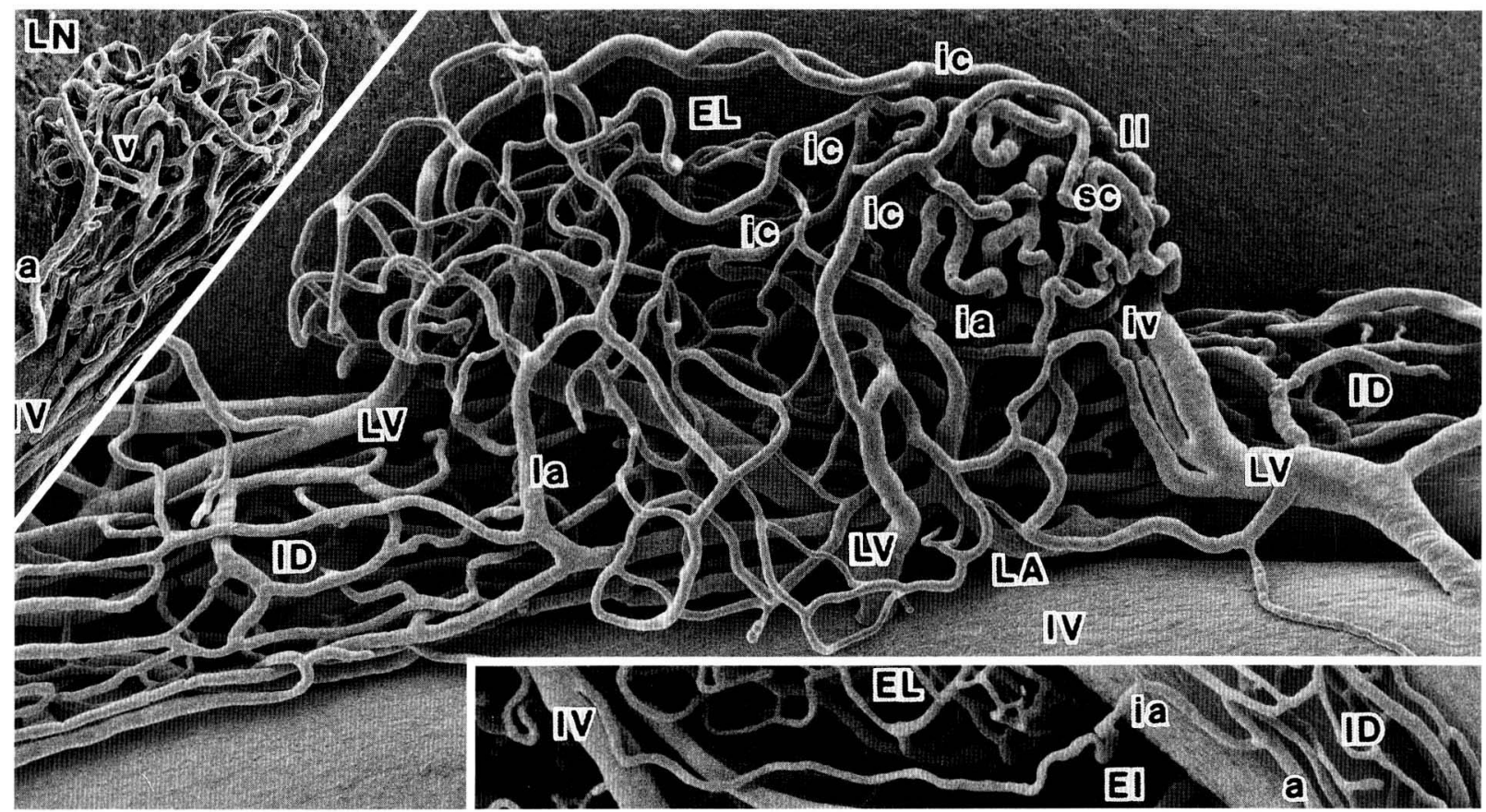

Fig. 16. A periductal lobe $(E L)$ containing a rare lateral intralobular islet $(I I)$ with few portal vessels. Note that the islet solely issues insulo-venous vessels ( $i c$ and $i v$ ). Upper Inset shows an isolated and partially microdissected intrapancreatic solitary lymph node $(L N)$, characterized by high-endothelial venules $(v)$ located deep in the node. Lower Inset shows an extralobular islet consisting of a U-shaped single capillary loop (EI). For other abbreviations, see Table $1 . \times 155$, upper Inset: $\times 70$, lower Inset: $\times 110$

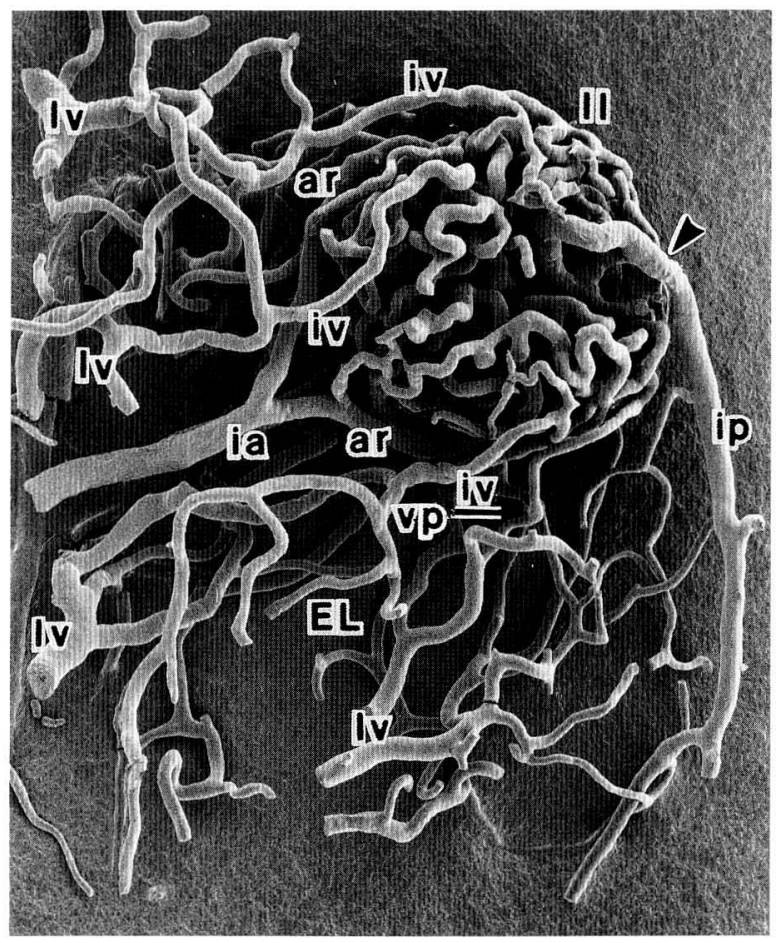

Fig. 17. A lateral intralobular islet $(I I)$ exposed by microdissection. The islet receives afferent rootlets $(a r)$ from its superficial aspect and issues a well-developed intralobular insulo-acinar portal vessel $(i p)$ from its deep aspect; some of the insulo-venous vessels $(i v)$ are thin and divided into two or more branches. Also note that one (iv) of the insulo-venous efferent vessels emits an insuloacinar portal branch $(v p)$ which continues into the lobular capillary plexus (EL). Arrowhead indicates constrictions imprinted near the orgin of the ip vessel. $\times 200$ 


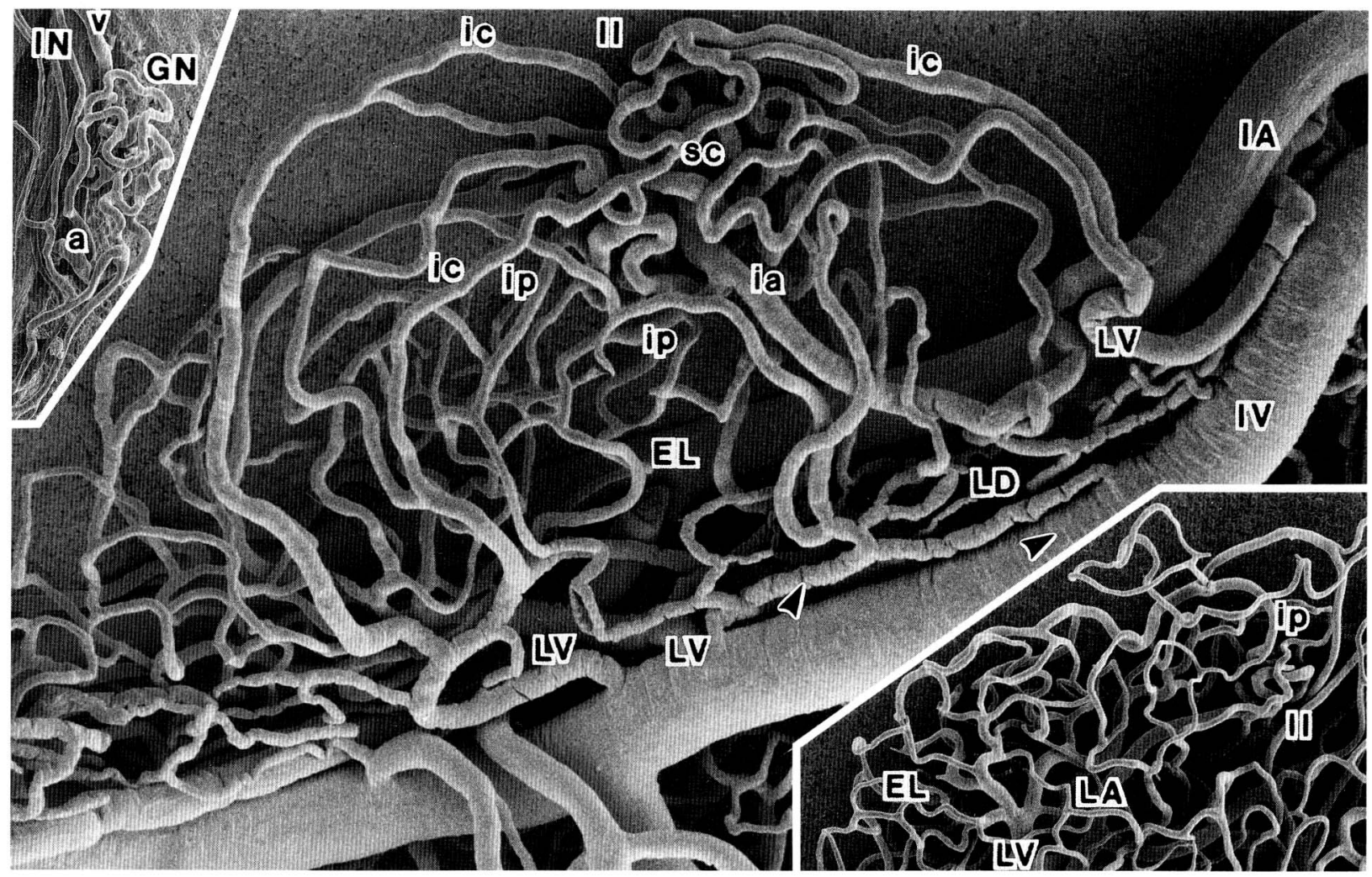

Fig. 18. A periductal lobule $(E L)$ containing an apical intralobular islet $(I I)$. This lobule receives few arterial branches from the interlobular artery. Note that the islet issues some long capillary-like insulo-venous vessels (ic), in addition to portal vessels (ip). Arrowheads indicate multiple circular constrictions imprinted in the interlobular vein $(I V)$ and thier branches. Upper Inset shows the capillary plexus of the nerve ganglion $(G N)$, which is provided with proper afferent $(a)$ and efferent $(v)$ vessels. Lower Inset shows a small-sized lateral intralobular islet $(I I)$, which emits a marked intralobular insulo-acinar portal vessel (ip) supplying almost all capillaries of the lobule $(E L)$. For other abbreviations, see Table $1 . \times 230$. upper Inset: $\times 160$, lower Inset: $\times 140$

in the lobule. No arterio-venous anastomosis was noted in the lobule.

The lobular plexuses were frequently clustered into sublobar units, sublobes (Figs. 8, 10,11). Smaller sublobes consisted of a few lobules (Figs. 8, 10, 11), while larger ones of ten or more lobules. In these fused cases, the lobules were usually interconnected with each other by some capillaries - translobular capillaries (Figs. 8, 11, 15).

The lobules, including those forming sublobes, were estimated to total 5,000 or more $(3,000$ or more in the left lobe, 1,500 or more in the right lobe, and 500 or more in the central lobe) in each rat pancreas. Of these lobules, 800 or more were closely associated as periductal lobules with the interlobular ducts and common bile ducts (Figs. 9, 10, 13-20, 23, 25, 26); the remaining ones were situated as peripheral lobules apart from the parent interlobular ducts (Figs. 8, 9, $21,24)$. In general, the periductal lobules (average long diameter, $0.82 \mathrm{~mm}$ ) were smaller than the peripheral lobules (average long diameter, $1.02 \mathrm{~mm}$ ) (Fig. 9).

\section{Position, size and occurrence of the endocrine islets}

The blood vascular plexuses of the endocrine islets were more or less conglomerated structures of spherical or ovoid shape, occasionally elongated or dumpbellshaped. The insular plexuses were characterized by their sinusoidal capillaries with conspicuously rounded impressions of nuclei (Fig. 27) and by their denser construction than the lobular and other vascular plexuses (Figs. 6-26).

Small islet plexuses consisted of a single or a few sinusoidal vessels (Figs. 27, 28), while large ones contained numerous capillaries and measured $900 \mu \mathrm{m}$ or more in long diameter (Fig. 13). Small islets with a diameter shorter than $30 \mu \mathrm{m}$ could only be identified with the scanning electron microscope, and 


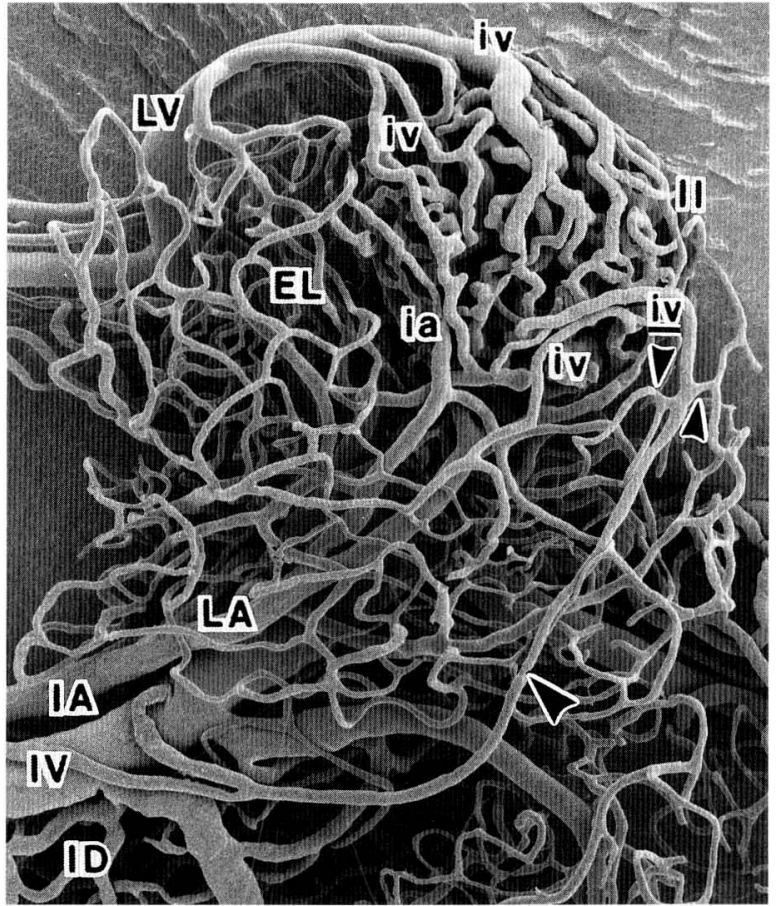

Fig. 19. An apical intralobular islet $(I I)$ which issues a long insulo-venous drainage vessel (iv and large arrowhead). This efferent vessel issues two insulo-acinar portal branches (small arrowhead) continuous with the lobular capillaries. For other abbreviations, see Table 1 . $\times 160$ were usually overlooked under the binocular light microscope. For this reason, the findings of small islets will be described separately in a later section.

Islets with a diameter longer than $30 \mu \mathrm{m}$ were estimated, in each pancreas, to count 400 or more (Table 2). Of there islets, 210 or more were located within the lobules as intralobular islets; the remaining 190 or more were observed in the interlobular spaces as the extralobular (interlobular) islets (Table 2).

The intralobular islets were further classified according to their positions within a lobule into basal intralobular (Figs. 14, 15), lateral intralobular (Figs. 16, 17), apical intralobular (Figs. 9 left-upper and right-lower Insets, $10,18,19,25,26)$ or deep intralobular (Figs. 20, 21) islets. The extralobular islets were also subdivided into periductal and heterotopic islets, the former being closely associated with a secretory duct, including the common bile duct (Figs. 6 Inset, 12, 12 lower Inset, 15 Inset, 23), the latter being situated apart from a duct (Figs. 12 upper Inset, 22, 22 Inset, 24 upper and lower Insets).

Occurrences of such classified islets were similar among different cases; those from a male rat are shown as an example in Table 2 together with their sizes.

\section{Intra-insular blood vessels}

In accordance with the light microscopic findings of India ink-injected tissue samples (see above), the insular complex basically consisted of inner sinusoidal capillary (parenchymal) plexus and outer fine capillary (capsular) meshwork (Figs. 12, 12 upper and lower Insets, 24 upper Inset). The parenchymal

Table 2. Type, size and occurence of the endocrine islets in the pancreas of an adult male rat weighing $400 \mathrm{~g}$.

\begin{tabular}{lccccccccccc}
\hline $\begin{array}{l}\text { Size of islet } \\
\text { (long diameter) }\end{array}$ & \multicolumn{3}{c}{$30-100 \mu \mathrm{m}$} & \multicolumn{3}{c}{$101-300 \mu \mathrm{m}$} & \multicolumn{3}{c}{$301-900 \mu \mathrm{m}$} & Total \\
Pancreatic lobe & RP & CP & LP & RP & CP & LP & RP & CP & LP \\
\hline Number of intralobular islets & 28 & 11 & 61 & 20 & 10 & 41 & 15 & 8 & 24 & 218 \\
$\quad$ Apical intralobular islets) & $(10)$ & $(4)$ & $(21)$ & $(7)$ & $(4)$ & $(14)$ & $(6)$ & $(5)$ & $(10)$ & $(81)$ \\
$\quad$ Lateral intralobular islets) & $(6)$ & $(2)$ & $(13)$ & $(4)$ & $(2)$ & $(9)$ & $(2)$ & $(1)$ & $(3)$ & $(42)$ \\
$\quad$ (Basal intralobular islets) & $(9)$ & $(3)$ & $(19)$ & $(7)$ & $(3)$ & $(12)$ & $(5)$ & $(2)$ & $(8)$ & $(68)$ \\
$\quad$ (Deep intralobular islets) & $(3)$ & $(2)$ & $(8)$ & $(2)$ & $(1)$ & $(6)$ & $(2)$ & $(0)$ & $(3)$ & $(27)$ \\
Extralobular islets & 31 & 14 & 49 & 23 & 11 & 37 & 8 & 4 & 13 & 190 \\
$\quad$ (Periductal islets) & $(23)$ & $(11)$ & $(36)$ & $(18)$ & $(8)$ & $(28)$ & $(5)$ & $(3)$ & $(9)$ & $(141)$ \\
$\quad$ (Heterotopic islets) & $(8)$ & $(3)$ & $(13)$ & $(5)$ & $(3)$ & $(9)$ & $(3)$ & $(1)$ & $(4)$ & $(49)$ \\
Total & 59 & 21 & 110 & 43 & 21 & 78 & 23 & 12 & 37 & 408 \\
\hline
\end{tabular}

$C P$ central lobe, $L P$ left lobe, $R P$ right lobe (see Table 1). 


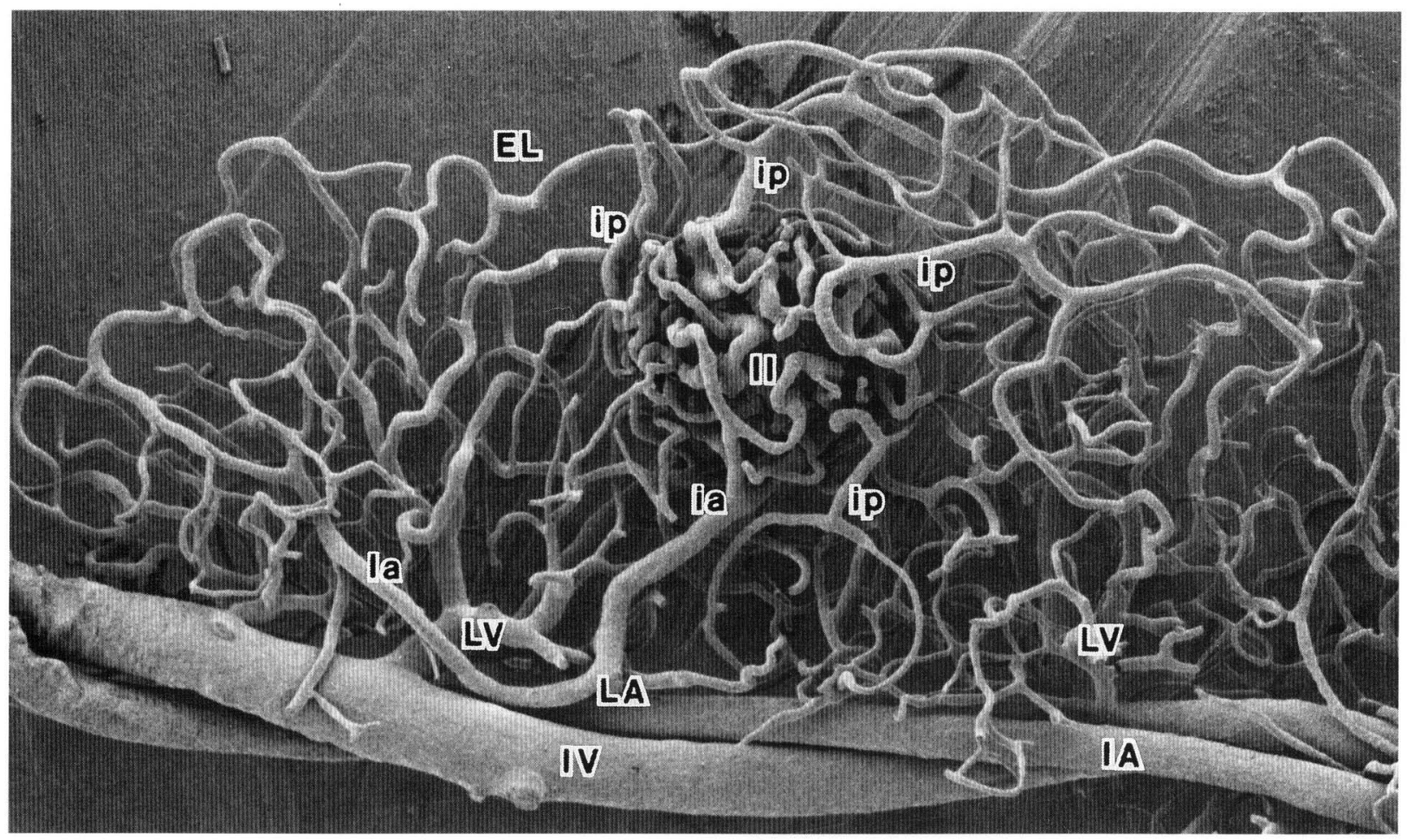

Fig. 20. A deep intralobular islet $(I I)$. Note that all efferent vessels from the islet represent the intralobular insulo-acinar portal vessels $(i p)$ continuing to the lobular plexus $(E L)$. For other abbreviations, see Table 1 . $\times 190$

plexus usually contained some fine (anastomosing) capillaries intervening between sinusoidal capillaries.

The insular complex received one or more afferent vessels from adjacent arteries (Figs. 14-26). These afferent vessels branched into finer vessels (afferent rootlets) between the capsular meshwork and parenchymal plexus, ran in this layer, and then continued into the parenchymal plexus (Figs. 17, 24 upper Inset).

The parenchymal plexus issued superficial efferent rootlets from its surface and deep efferent rootlets from its deep areas (Fig. 24 upper Inset). These rootlets joined each other and formed the capsular meshwork, which emitted the efferent vessels of an islet (Fig. 12 upper and lower Insets). In islets larger than $300 \mu \mathrm{m}$ in diameter, one or more of the deep efferent rootlets were usually thick and directly continued into the efferent vessels (Figs. 12, 17, 24 upper Inset).

On some occasions, the capsular network additionally received one or more arteries or afferent rootlets (capsular afferent rootlets) from the superficial or deep aspect (Fig. 12 upper and lower Insets).

The afferent artery of an islet occasionally showed a sharply delineated ring-like constriction at its origin (Fig. 15). Very rarely, one or two of the afferent vessels penetrated through an intralobular or extra- lobular islet; sach an artery, after penetrating the islet, gave rise to an interlobular or intralobular artery (Fig. 21 Inset).

\section{Insulo-acinar portal and insulo-venous efferent vessels of extralobular islets}

In the periductal and heterotopic islets, the capsular capillary network was fully developed, and emitted efferent vessels which usually drained, as the insulovenous efferent vessels, into the lobular, interlobular, periductal or proper interlobular veins (Fig. 12, upper and lower Insets). Occasionally, some or all of the efferent vessels from an extralobular islet drained, as extralobular insulo-acinar portal vessels, into the capillaries of an adjacent lobule or lobules (Figs. 8, 22, 24 lower Inset).

On rare occasions, the efferent vessels of an extralobular islet branched in the interlobular spaces into finer vessels which continued into interlobular capillaries (Fig. 12 upper Inset). Also as rarely did they receive, at their origin or close to the islets, the venous branches originating in adjacent lobules or interlobular tissue spaces (Fig. 15 Inset).

An extralobular islet was occasionaly found adhered to an adjacent lobules. Some or all of the efferent 


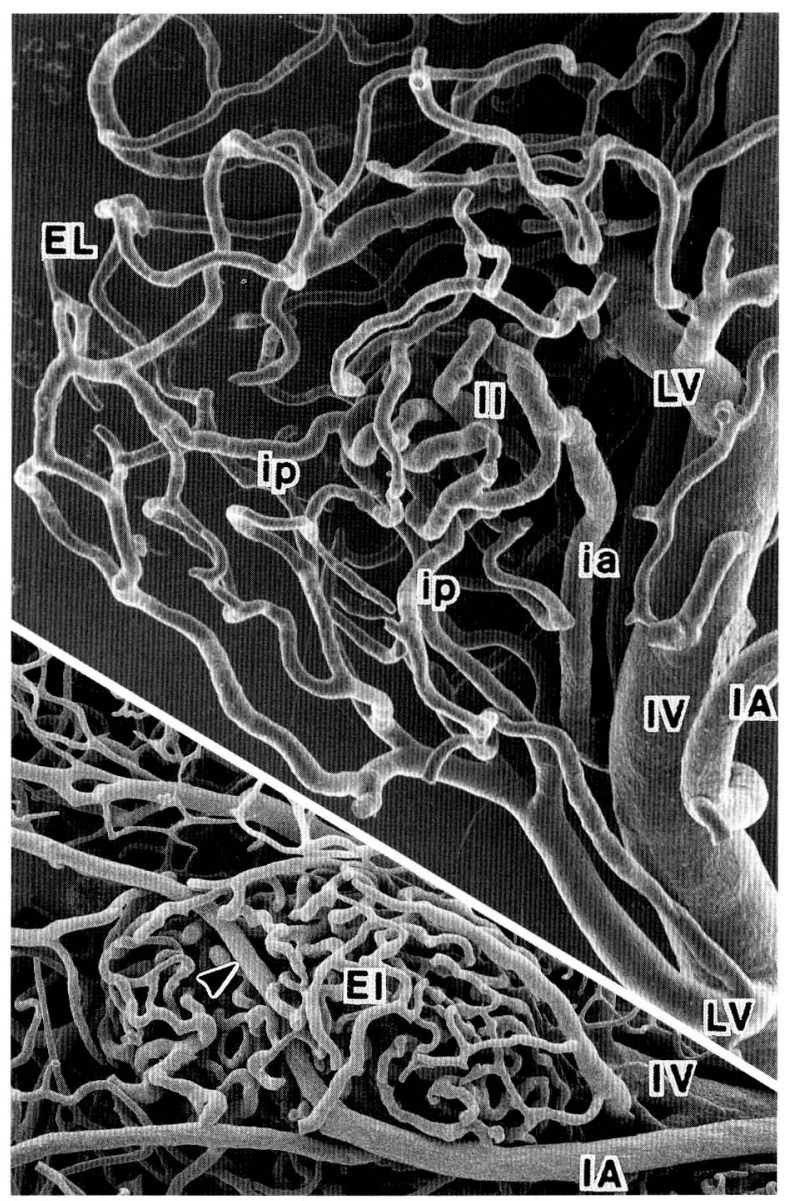

Fig. 21. A deep intralobular islet $(I I)$ of a small size, receiving an afferent artery $(i a)$ and issuing only intralobular insulo-acinar portal vessels $(i p)$. Inset shows a rare arterial branch (arrowhead) penetrating a heterotopic interlobular islet $(E I)$. For other abbreviations, see Table 1. $\times 340$, Inset: $\times 150$

vessels of such islets continued, as the extralobular insulo-acinar portal vessels, into the capillaries of the adhered lobule or lobules; the remaining efferent vessels drained, as the insulo-venous efferent vessels, into adjacent intralobular veins (Figs. 22 Inset, 23).

Ring-like constrictions sometimes imprinted in the insulo-venous efferent vessels (Figs. 12, 12 upper Inset) and also in the extralobular insulo-acinar portal vessels.

Insulo-acinar portal and insulo-venous drainage vessels of intralobular islets

The intralobular islets basically possessed no capsu-

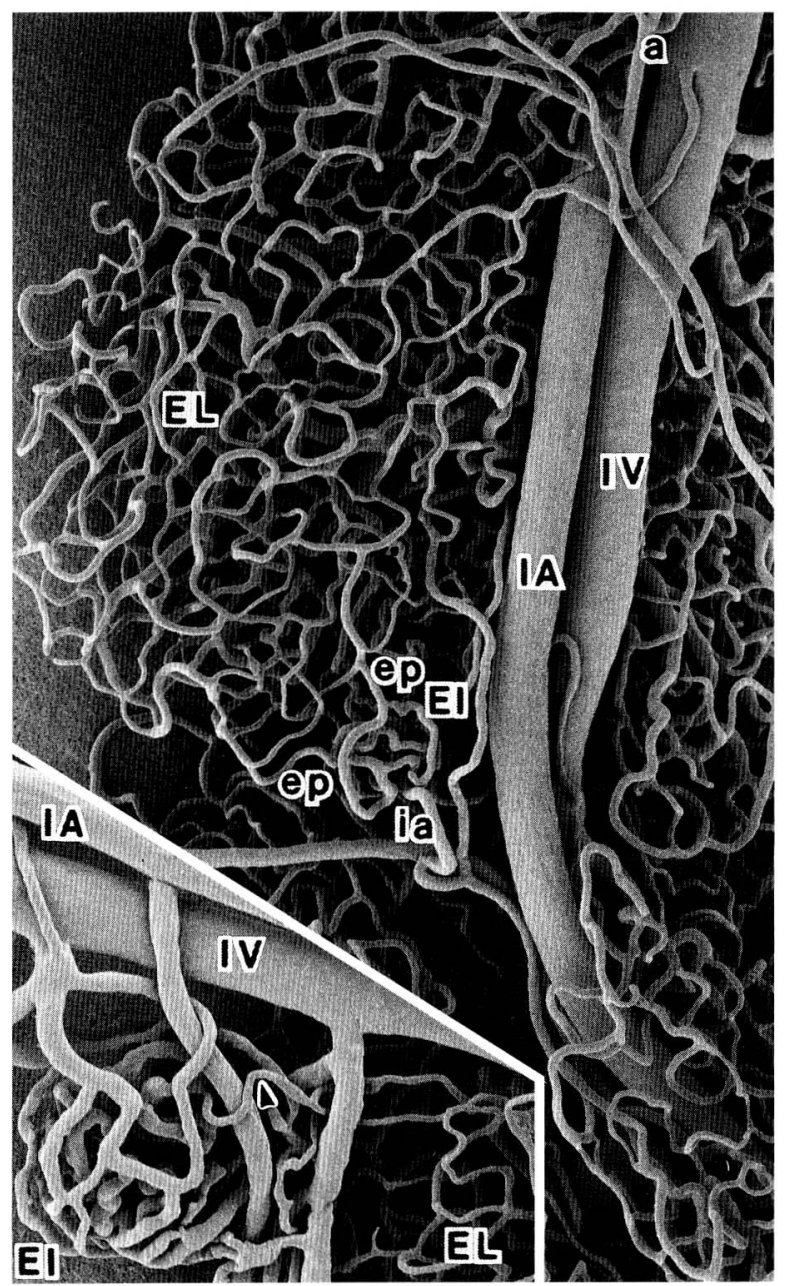

Fig. 22. A heterotopic islet $(E I)$, which issues extralobular insulo-acinar portal vessels (ep). Inset shows another heterotopic islet issuing a thin extralobular insulo-acinar portal vessel (arrowhead). For other abbreviations, see Table $1 . \times 115$, Inset: $\times 145$

lar meshworks, and emitted their efferent vessels directly from the parenchymal plexuses. This pattern was typical in the deep intralobular islets (Figs. 20, 21). In the basal, lateral and apical intralobular islets, however, a layer of capsular capillaries usually was recognized in their aspect exposed to the lobular surface (Figs. 14-16, 18). In these islets, thus, the insulo-efferent vessels arose from either the remnants of the capsular meshwork or the parenchymal plexus (Figs. 14-16, 18).

Regardless of their position in the lobule, the efferent vessels of islets continued - as insulo-venous vessels - into the intralobular veins, or branched as intralobular insulo-acinar portal vessels - into 
the lobular capillaries (Figs. 13-15, 17, 18). The deep islets typically drained into the lobular capillaries as intralobular insulo-acinar portal vessels (Figs. 20, 21).

The insulo-venous drainages were occasionally thin and long vessels running in a superficial layer of the lobule, and continuing to an intralobular veins (Fig. 10). Frequently, a thin efferent vessel divided into two or more branches befor entering a vein (Fig. 17). Also frequently, a thin insulo-venous vessel issued a few branches (insulo-acinar portal branches) which continued into lobular capillaries (Figs. 19, 23 Insets). However, such thin insulo-venous vessels rarely formed rink-like loops (Fig. 10, Inset). It was farther frequently observed that the insulo-venous drainages were slender capillary-like vessels, and directly entered intralobular or lobular veins (capillary-like insulo-venous efferent vessels) (Figs. 16, 18).

The intralobular insulo-acinar portal vessels, including those of the deep islets, were sometimes thick and long. They ran in a superficial or deep layer of the lobule and supplied the lobular capillaries of a region far from the islet (Figs. 17, 20).

The basal, lateral and apical intralobular islets only rarely emitted typical insulo-acinar portal vessels. In these islets, usually all efferent vessels were represented by fine (capillary-like) insulo-venous vessels which showed few divisions on their way to the intralobular or lobular veins (Fig. 16).

Some shallow ring-like constrictions were occasionally imprinted on the portal vessels at or near their origins (Fig. 17). Similar constrictions were occasionally noted even in the insulo-venous vessels.

\section{Translobular insulo-acinar portal vessels}

On some occasions, a basal or lateral intralobular islet issued one or two translobular insulo-acinar portal vessels. These vessels arose either from the capsular meshwork or from the parenchymal plexus of the islet, and ran into an adjacent lobule or lobules to there continue into the lobular capillaries (Fig. 24). On rare occasions, such translobular portal vessels arose from a common trunk with intralobular insuloacinar portal vessels.

\section{Efferent vessels of intralobular islet occupying a large portion of the lobule}

Regardless of type and size, an intralobular islet frequently occupied half or more of a lobule (Figs. 9 right-lower Inset, 25, 26). In such a case, it was usual for two or more insulo-venous efferent vessels to be fully developed and directly continue into the intralobular or lobular veins. It was also usual for some of

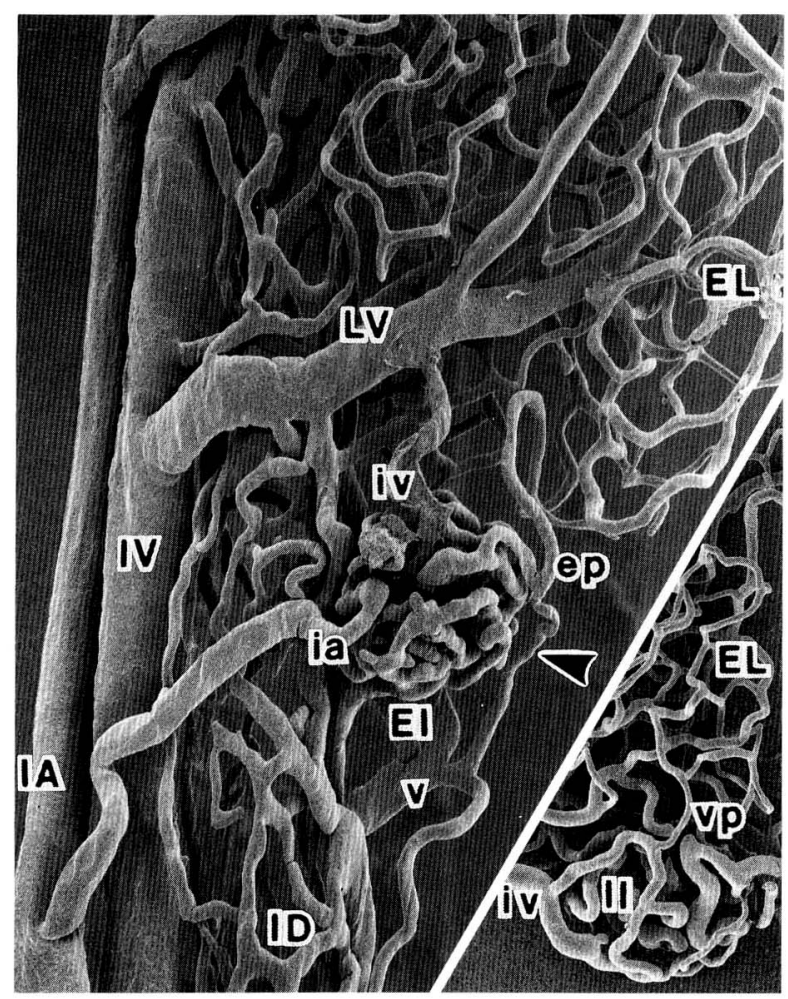

Fig. 23. A periductal islet $(E I)$ emiting an extralobular insulo-acinar portal vessel (ep). This portal vessel, in its turn, communicates (arrowhead) with a venous branch $(v)$ along the periductal plexus (ID). Inset shows an insuloacinar portal branch $(v p)$ from an insulo-venous vessel (iv). For other abbreviations, see Table 1 . 180, Inset: $\times 120$

the insulo-venous efferent vessels to issue, at or near their origins, one or more vessels (insulo-acinar portal braches) which divided into the lobular capillaries (Fig. 25). Occasionally, the insulo-acinar portal branches were recognized as fine lobular capillaries (Fig. 26).

The lobules whose large portions were thus occupied by an islet received few arterial branches; all or almost all of the lobular capillaries were derived from the insulo-acinar branches of the insulo-venous efferent vessels (Figs. 9 right-lower Inset, 25, 26).

Multiple constristions were occasionally noted even in the insulo-venous efferent vessels in these cases (Fig. 26).

\section{Small-sized islets and their efferent vessels}

Islets with a diameter shorter than $30 \mu \mathrm{m}$ consisted of a single or a few sinusoidal capillaries which were usually twisted or U-shaped (Figs. 16 Inset, 27, 28). In a scanning survey, these islets were frequently re- 


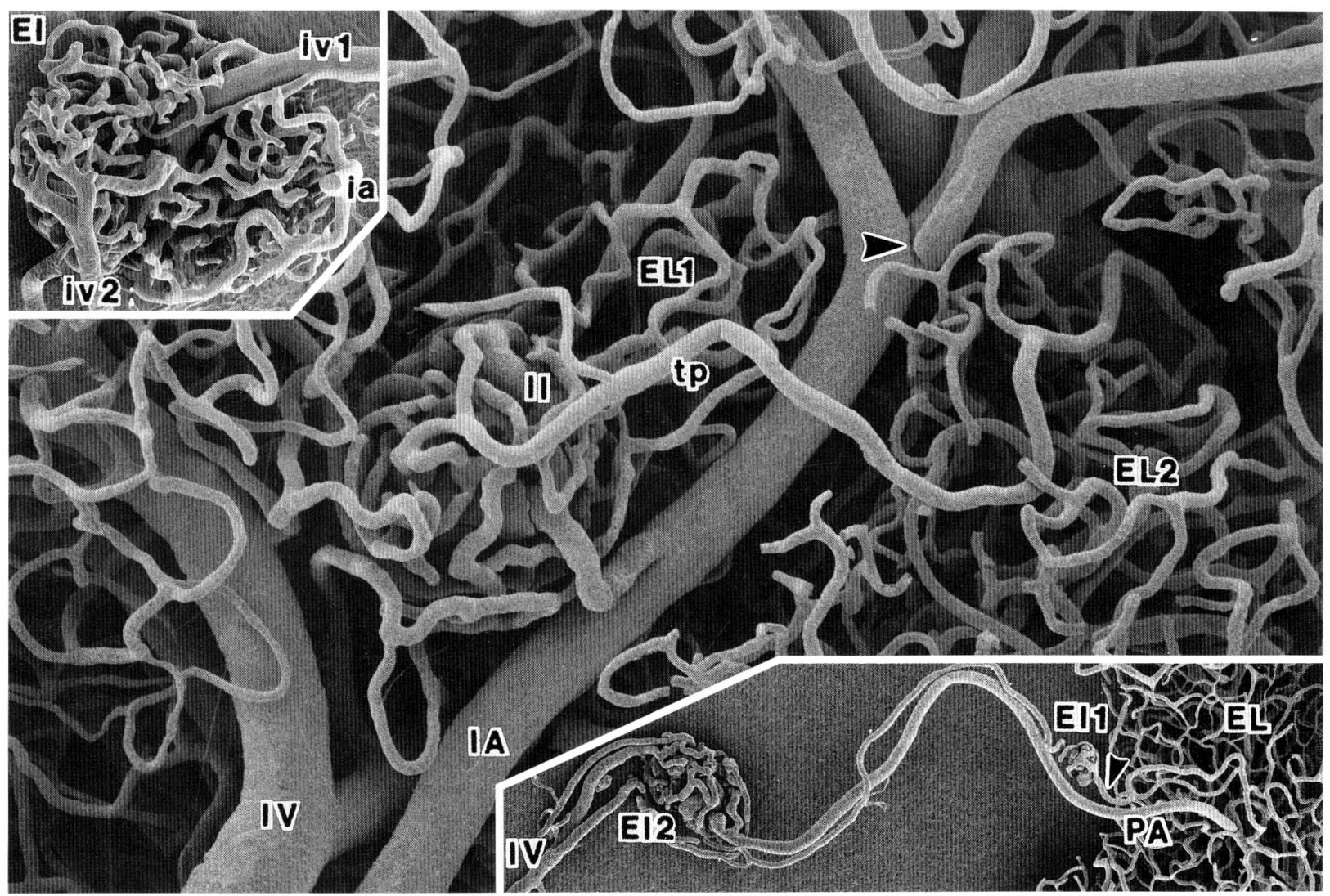

Fig. 24. A translobular insulo-acinar portal vessel $(t p)$. Note that this portal vessel arises from an islet $(I I)$ in an EL1 lobule and runs into adjacent EL2 lobule to supply it. Arrowhead indicates a sharp and deep constriction imprinted at the origin of the interlobular arterial branch. Upper Inset shows a dissected aspect of a heterotopic islet $(E I)$ emitting two marked insulo-venous drainage vessels (iv1, iv2). Note that the $i v 1$ arises from the deep portion and the $i v 2$ from the superficial aspect of the islet. Lower Inset shows two heterotopic islets (EI1, EI2), which are supplied by a lobular penetrating artery $(P A)$. The EI1 islet issues a marked extralobular insuloacinar portal vessel (arrowhead) to the penetrated lobule $(E L)$, while the EI2 islet drains into the interlobular vein $(I V)$. For other abbreviations, see Table $1 . \times 280$, upper Inset: $\times 135$, lower Inset: $\times 80$

presented by the deep islets (Fig. 27); it was rather rare that they were located extralobularly (Fig. 16 Inset). The exact frequency of occurrence of these small-sized islets remained unknown since they were usually overlooked in binocular dissection prior to the scanning observations.

The efferent vessels of the small-sized intralobular islets always drained as the intralobular insulo-acinar portal vessels into the lobular capillaries (Figs. 27, 28). Occasionally, thses portal vessels were considerably long and terminated far from their parent islet (Figs. 18 Inset, 27). The efferent vessels of the smallsized extralobular islets drained into adjacent interlobular capillaries or venules (Fig. 16 lower Inset).

Some ring-like constrictions were occasionally noted even in the portal vessels of the small-sized islets (Fig. 27).

\section{DISCUSSION}

This study indicates that the adult rat pancreas contains 5,000 or more exocrine lobules and 400 or more endocrine islets with a diameter longer than 30 $\mu \mathrm{m}$, and that of these islets, 210 or more are located intralobulaly, the remaining 190 or more, extralobularly (or interlobularly). It also confirms that the intralobular islets usually issue marked insulo-acinar portal vessels continuous with the lobular capillaries in addition to some insulo-venous efferent vessels directly draining into veins; the extralobular isletes usually issue only insulo-venous efferent vessels. By scanning electron microscopy of vascular casts, BONNER-WEIR and ORCI (1982) reported that the rat pancreas contains about 300 islets with diameters 
longer than $60 \mu \mathrm{m}$. However, little information on the positions of the islets was included in their study (BONNER-WEIR and ORCI, 1982).

Occurrence of the insulo-acinar portal vessels (or direct connections between the insular and lobular capillaries) has been demonstrated in man by light microscopy of tissue sections (WHARTON, 1932) and scanning microscopy of vascular casts (MURAKAMI et al., 1992), in the monkey by scanning microscopy of vascular casts (Fujita and MuRAKAMI, 1973), in the horse by light microscopy of India ink-injected tissue samples (Fujita, 1973; Fujita and Watanabe, 1973), in the dog by scanning microscopy of vascular casts (Fujita et al., 1976; OHTAnI, 1988), in the rabbit by light microscopy of India ink-injected preparations (THIEL, 1954) and by scanning microscopy of vascular casts (OHTANI, et al., 1983), in the cat by scanning microscopy of vascular casts (SYED ALI, 1984), in the rat by scanning electron microscopy of vascular casts (FUJITA et al., 1976; BONNER-WEIR and ORCI, 1982; OHTANI et al., 1986), and in the mouse by light microscopy of India ink-injected tissue samples (BECK and BERG, 1931) and by intravital microscopy of living tissues (MCCUSKEY and CHAPMAN, 1969). Occurrence of the insulo-acinar portal vessels has been demonstrated even in lower vertebrates such as snakes by scanning microscopy of vascular casts (SYED ALI et al., 1991).

Occurrence of the insulo-venous vessels has been demonstrated in the mouse by light microscopy of India ink-injected preparations (BECK and BERG, 1931) and by intravital microscopy of living tissues (BRUNFELD et al., 1958; BUNNAG et al., 1963), and in the rat by scanning microscopy of vascular casts (BONNER-WeIR and ORCI, 1982; OHTANI et al., 1986). The coexistence of portal and venous drainages has been suggested in the mouse by light microscopy of India ink-injected tissue samples (BECK and BERG, 1931), and evidenced in the rat by scanning microscopy of vascular casts (OHTANI et al., 1986).

Recently, we reinvestigated the pancreatic vascular casts of man, monky and other mammals including the mouse, guinea pig, rabbit, cat dog, pig and cattle under the scanning electron microscope, paying special attention to the occurrence of the intralobular and extralobular islets and their efferent vessels. The species differences in these regards were conspicuous. In man, most of the islets are intralobular in location and emit only insulo-acinar portal vessels; a few islets are located in the interlobular tissue spaces to issue the insulo-venous efferent vessels continuous with the interlobular veins (MURAKAmI et al., 1992). In the mouse, as in the rat, many islets are extralobular in position, and drain into the interlobular

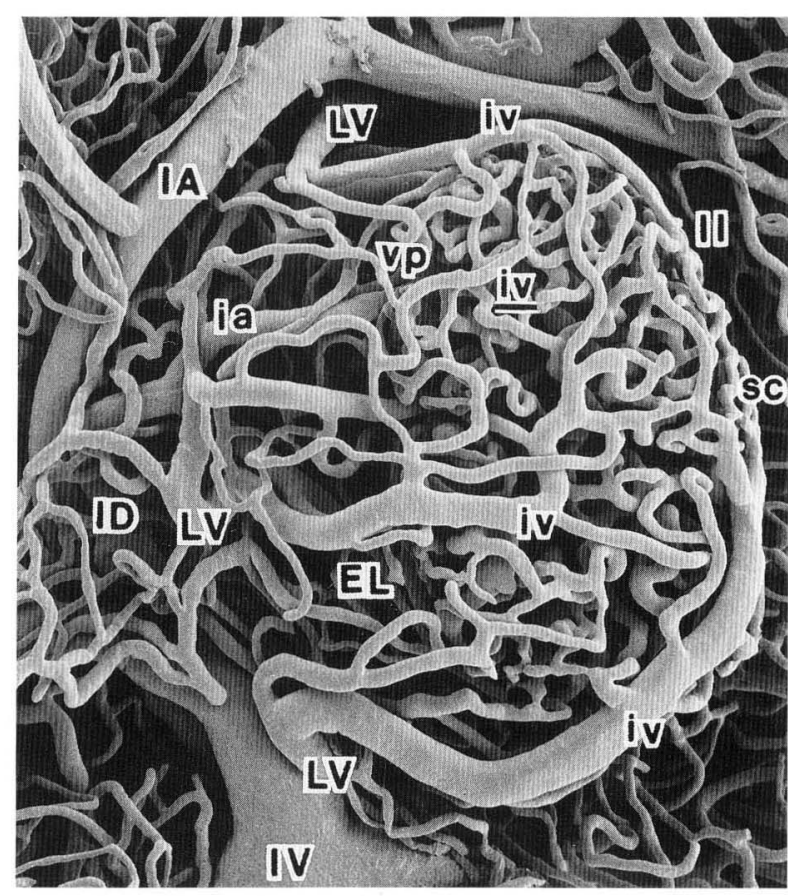

Fig. 25. A periductal lobule (EL) which is largely occupied by an apical intralobular islet $(I I)$. Note that one (iv) of the insulo-venous vessels (iv) issues an insuloacinar portal branch $(v p)$ which continues into the lobular capillaries. For other abbreviations, see Table $1 . \times 170$

veins; the intralobular islets in this animal usually take a basal or lateral position in the lobule and have both drainage into portal vessels and into intralobular veins. In the guinea pig, many islets are extralobular and drain into the interlobular veins; the intralobular islets usually take an apical or deep position within the lobule and issue portal vessels; the basal intralobular islets have both drainage into portal vessels and intralobular veins. In the rabbit, cat, dog, pig, cattle and Formosan monkey, as in man, extralobular islets are rather rare; almost all of the islets appear in a deep intralobular position, and issue only the portal vessels. Some of these findings have already been introduced in our previous paper (MURAKAmI et al., 1992).

This paper demonstrates that in the rat pancreas, the insulo-venous drainage vessels are sometimes slender and may issue insulo-acinar portal branches which supply lobular capillaries. Furthermore, the insulo-venous vessels can divide into some fine loops before they empty into the veins. These findings suggest that part of the insulo-venous efferent vessels are portal in nature.

This paper demonstrates that, in the rat pancreas, the intralobular islets are usually scattered in rela- 


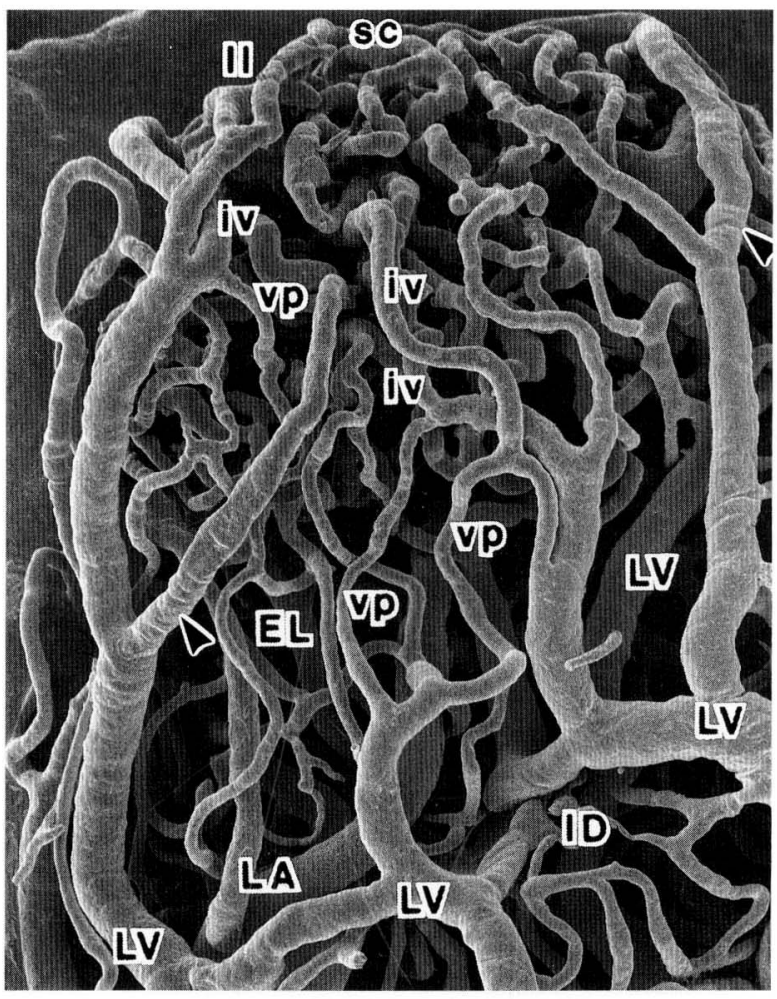

Fig. 26. A periductal lobule $(E L)$ almost totally occupied by an apical intralobular islet $(I I)$. Note that some of the insulo-venous vessels $(i v)$ issue minute vessels $(v p)$ which are as thick as fine capillaries. Arrowheads indicate vascular contractions imprinted in the insulo-venous drainage vessels. For other abbreviations, see Table 1 . $\times 250$

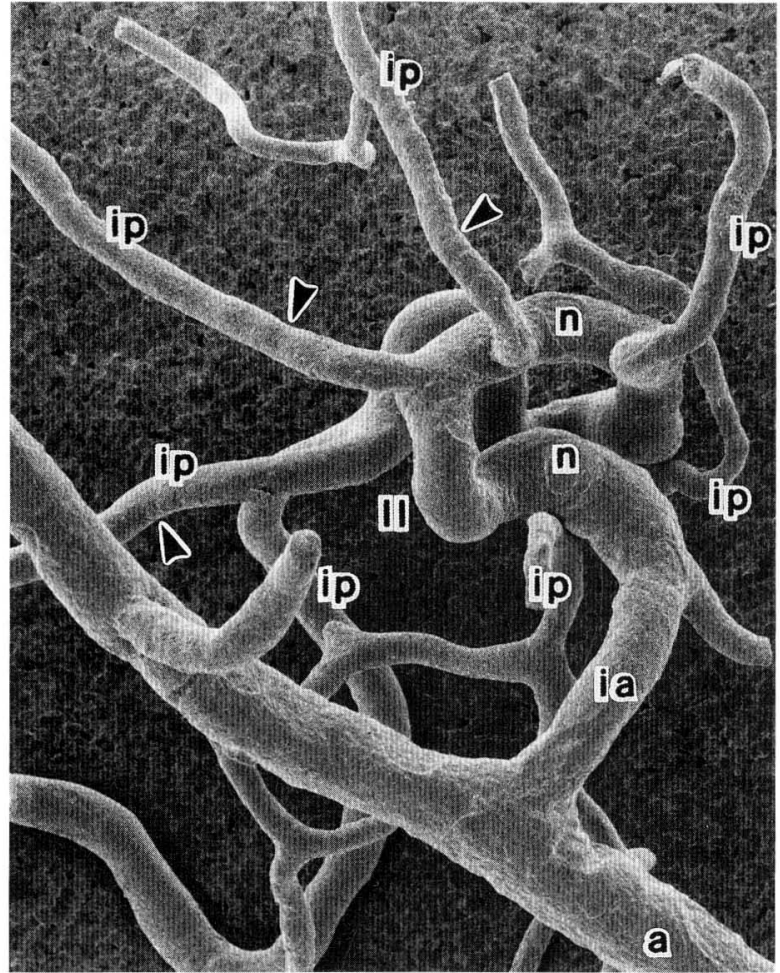

Fig. 27. An isolated deep intralobular islet $(I I)$ of a small size, consisting of a twisted single sinusoidal vessel. This islet issues seven or more portal vessels ( $i p)$, and the twisted vessel shows round nuclear impressions $(n)$. Arrowheads indicate the constrictions in the portal vessels (ip). For other abbreviations, see Table 1. ×630

in an islet, and that these intra-insular portal vessels are homologous with the intralobular insulo-acinar portal vessels (MuraKami et al., 1992). It can also be said that the insulo-venous efferent vessels draining the capsular meshwork of the extralobular islet are homologous with the lobular veins. The extralobular and translobular insulo-acinar portal vessels may represent modified forms of the translobular capillaries.

This paper demonstrates that the rat islet tends to receive afferent rootlets from its superficial aspect and emit efferent rootlets from both its deep and superficial layers. This finding supports our proposal that blood in the islet flows first to the area of A and D cells, and then to the area of B cells. Our idea suggests that the $\mathrm{B}$ cells' release of insulin is regulated by glucagon and somatostatin from $\mathrm{A}$ and $\mathrm{D}$ cells more effectively than otherwise by this intra-insular microcirculatory design (Fujita and Murakami, 1973).

In their scanning microscopy of vascular casts, BONNER-WEIR and ORCI (1982) claimed that in the rat

It can be said that a portal system exists between the parenchymal plexus and the capsular meshwork 
islet, the blood, inversely to our "rule", reached the islet center first and then flowed to the A-D cell mantle. OHTAni et al. (1986), however, confirmed by intravital microscopy of the rat pancreas injected with a fluorescent tracer, that the blood flowed from the A-D cell mantle to the B cell core. Our recent scanning investigation of the casts of rat pancreata insufficiently injected with resin supports this result by OHTAni et al. (1986) (Miyake et al., 1992).

Our previous scanning microscopy of vascular casts has demonstrated that the human islets which are known for their inconsistent arrangement of A, B and D cells show a markedly indecisive pattern of microcirculation (MuraKaMI et al., 1992). In monkey islets containing A and D cells in the core and B cells in the cortex, the afferent rootlets usually run deep into the core, while the efferent ones arise in the superficial layer of the islet (Fujita and Murakami, 1973).

Throughout humans and animals, the sizes of the islets are rather consistent. In humans, the islets usually have a diameter of 100-150 $\mu \mathrm{m}$ (MURAKAMI et al., 1992). Many rat islets have a diameter as large as 100-300 $\mu \mathrm{m}$ (see above). In the guinea pig, rabbit, cat, dog, pig, cattle and monkey, the sizes of the islets roughly accord with those of the human or rat. This consistency in islet sizes throughout the species, apparently without any relation to body size, may be accounted for by the efficiency of microcirculation, i.e., by regarding the islet as a vascular organ. A similar or stricter consistency in organ size among species may be observed in another vascular organ, the renal glomerulus.

The insulo-acinar portal system conveys high concentrations of insular hormones to the exocrine tissue, and presumably regulates the secretory activities of the exocrine acini and intercalated ducts as extensively reviewed in man and in various animals (Fujita and Watanabe, 1973; Fujita and Kobayashi, 1979; HeNDERSON et al., 1981; HENDERSON, 1983; TRIMBLE et al., 1985; OHTANi, 1988; MURAKAMI et al., 1992). In the rat pancreas, as described above, one of twentythree lobules (5,000 lobules/210 islets) contained an islet clearly idetifiable in the cast samples. This does not exclude that the remaining lobules lacked islets because such small-sized islets as shown in the Figures 18 Inset, 27 and 28 were usually overlooked. Nevertheless, it is obvious that in the rat pancreas, a considerable number of lobules are devoid of an islet. The lobules containing an islet were usually small in size, though their whole capillary beds frequently were entirely supplied by the portal vessels. It is thus suggested that in the rat the insular control over the exocrine pancreas is limited to rather small areas.

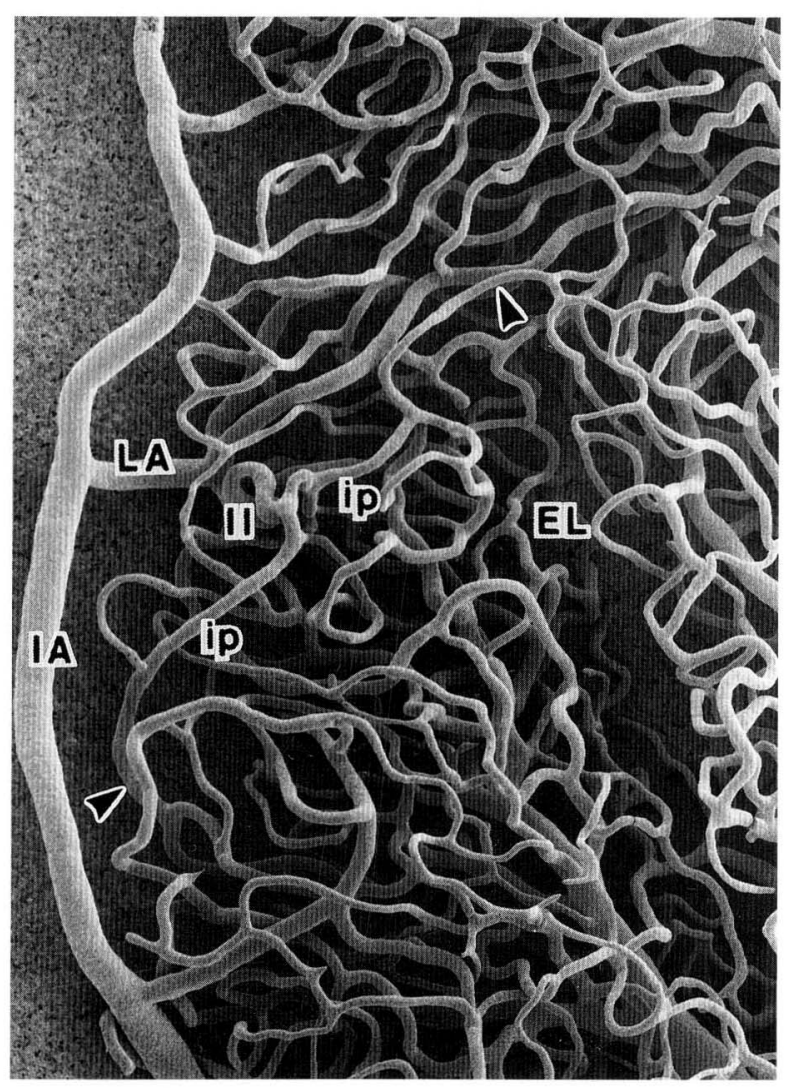

Fig. 28. A small-sized basal intralobular islet consisting of a U-shaped single vessel $(I I)$. This islet issues two marked intralobular insulo-acinar portal vessels (ip), and some of their branches extend far (arrowhead) to supply remote lobular capillaries $(E L)$. For other abbreviations, see Table $1 . \times 185$

In spite of this limited distribution of the insuloacinar portal vessels, our data support the possibility that the lobular blood may preferentially flow through the portal route. We recently injected insufficient amounts of resin into the rat pancreas, and found that the insulo-acinar portal route was filled with the injected resin more promptly than the usual route via the acinar arteries (MIYAKE et al., 1992).

It was also noticed that the periductal plexuses of the extralobular ducts, especially those of mediumand large-sized interlobular ducts, are dense in meshwork. This finding suggests that the periductal plexuses may receive a small amount of blood to reabsorb water efficiently from the pancreatic juice.

In our previous casting of the monkey pancreas, marked constrictions were recognized in the insuloacinar portal vessels (FUJiTA and MURAKAMI, 1973). Similar constriction were also noted in the insulo- 


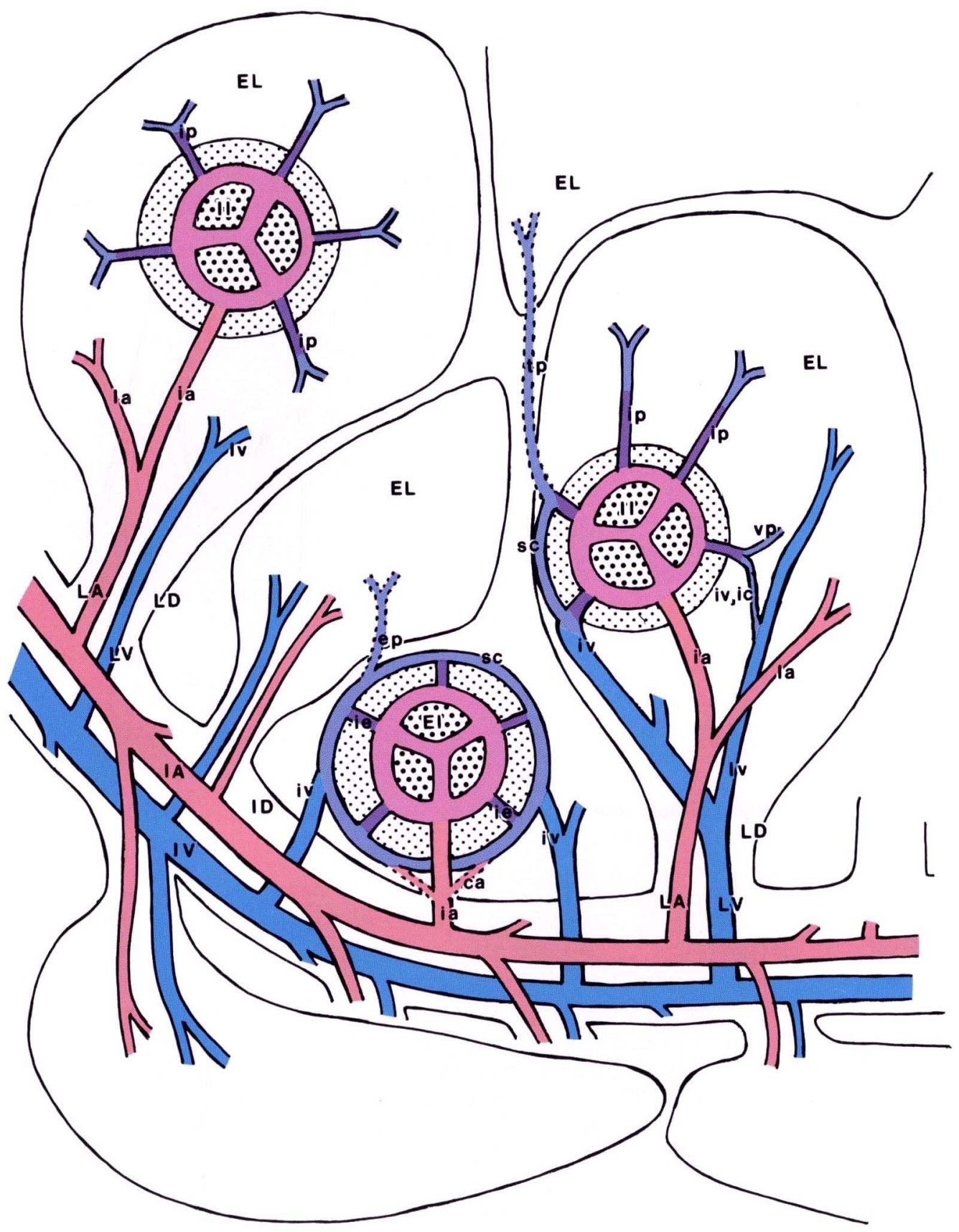

Fig. 29. A diagram showing the vascular arrangement of the rat pancreas. The insulo-capsular meshwork ( $s c$ ) of the extralobular islet $(E I)$ may be homologous with the lobular plexus $(E L)$. The intra-insular efferent rootlets (ie) of the $E I$ islet may be homologous with the intralobular insulo-acinar portal vessels (ip) of the intralobular islet $(I I)$. The extralobular insulo-acinar portal vessel $(e p)$ of the $E I$ islets may be homologous with the translobular insulo-acinar portal vessel $(t p)$ of the $I I$ islet. Also see text. For other abbreviations, see Table 1. 
acinar portal vessels of rat pancreas studied here. These constrictions suggest that the portal vessels are provided with circular smooth muscles which may regulate the blood flow from the islet to the lobular capillaries. SYED ALI (1984) replicated some circular constriction in the cat insulo-acinar portal vessels and suggested that this structure might due to the occurrence of pericytes as sphincters.

The spiral impressions in the hepatic portal vein may represent the portal spiral described by $\mathrm{BoOz}$ (1964), which are known to show a rhythmic pulsation (10-30/min) (Hebel and StromberG, 1976). The multiple constrictions recognized in the interlobular arteries and veins may have been imprinted by contractions of their walls during the heating procedure for the polymerization of injected resin. Noteworthy is the fact that the multiple consrictions are more clearly imprinted in the veins than in the arteries, suggesting that in the rat pancreas, the veins might be more contractile than the arteries to convey effectively the pancreatic venous blood to the portal spiral.

This paper moreover shows that in the rat pancreas, as in the human pancreas (MURAKAMI et al., 1992), the capillary plexus of exocrine lobules and that of extralobular secretory ducts (lobular ducts) have little communication. They are independent from each other in view of blood supply. Within the lobule, in contrast, the exocrine acini and intercalated and intralobular secretory ducts are supplied in common by homogeneously distributed lobular capillaries derived from the intralobular (acinar) arteries or the insulo-acinal portal vessels. The connections of the lobular capillaries with the interlobular ones are so fine that they may be insignificant in supplying the lobules.

It is generally believed that the branches of the hepatic portal vein are provided with no valves (BENNINGHOFF, 1930; HeBEL and STROMBERG, 1976). However, as shown above, marked V-shaped impressions were at times noted in the interlobular veins in rat pancreas, suggesting the occurrence of venous valves. The sharp and deep ring-like constrictions at the orgins of the interlobular arteries and the afferent vessels of the islets resemble in their forms those imprinted at the origins of the carotid body arteries (TAGUCHI, 1986). The carotid body arteries are provided with marked intra-arterial endothelial cushions at their origins, probably inhibiting the retrograde flow of arterial blood (TAGUCHI et al., 1992) or regulating the inflow of arterial blood into the carotid bodies (MCDONALD and LARUE, 1983).

LIFSON and LASSA (1981) injected silicone latex, India ink, hematoxylin and microsphere into the rabbit pancreas, and reported that the periductal plexus received blood from the lobular plexus. In our rat samples, as in the previously studied human samples (MuraKami et al., 1992), few channels were reproduced between the capillary plexuses of the exocrine lobules and the extralobular ducts. By scanning microscopy of replicated rat and rabbit pancreata, OHTANI $(1983,1988)$ reported that the islets sometimes emit efferent vessels continuous with the periductal capillary plexus. This "insulo-ductal portal system" was identified neither in our rat samples nor in our previously studied human samples (MURAKAMI et al., 1992).

The extremely rare penetrating arteries of islets may presumably be formed by the fusion of two or more islets. Big islets with a diameter longer than 500 $\mu \mathrm{m}$ usually have an A-D cell septum, suggesting fusion of the islets (unpublished data). Such a septum is also observed in the dumpbell-shaped islets (umpublished data). The lobular penetraing arteries and veins may be formed by the fusion of two or more lobules. These arteries and veins may therefore be originally interlobular.

\section{REFERENCES}

Beck, J. S. P. and B. N. BerG: The circulatory pattern in the islands of Langerhans. Amer. J. Pathol. 7: 31-35 (1931).

Benninghoff, A.: Venen. In: (ed. by) W. Möllendorff: Handbuch der mikroskopischen Anatomie des Menschen. VI/1. Blutgefäße und Herz • Lymphgefäße und lymphatische Organe - Milz. Julius Springer, Berlin, 1930 (p.131-160).

Bonner-WeIR, S. and L. ORCI: New perspective on the microvasculature of the islets of Langerhans in the rat. Diabetes 31: 883-889 (1982).

Booz, K. H.: Zur Morphologie und funktionellen Bedeutung einer "Spiralklappe" in der V. portae der Nagetiere. Anat. Anz. 115: 141-147 (1964).

Brunfeldt, K., K. Hunhammer and A. P. Skouby: Studies on the vascular system of the islets of Langerhans in mice. Acta Endocrinol. 29: 473-480 (1958).

Bunnag, S. C., S. Bunnag and N. E. Warner: Microcirculation in the islets of Langerhans of the mouse. Anat. Rec. 146: 117-123 (1963).

FuJiTA, T.: Insulo-acinar portal system in the horse pancreas. Arch. Histol. Jap. 35: 161-171 (1973).

Fujita, T. and S. Kobayashi: Proposal of neurosecretory system in the pancreas. An electron microscope study in the dog. Arch. Histol. Jap. 42: 277-295 (1979).

Fujita, T. and T. Murakami: Microcirculation of monkey pancreas with special reference to the insulo-acinar portal system. A scanning electron microscope study of vascular casts. Arch. Histol. Jap. 35: 255-263 (1973). 
Fujita, T. and Y. Watanabe: The effects of islet hormones upon the exocrine pancreas. In: (ed. by) $\mathrm{T}$. FuJiTA: Gastro-entero-pancreatic endocrine system-A cell-biological approach. Igaku-Shoin, Tokyo, 1973 (p. 164-173).

Fujita, T., Y.Yanatori and T. MuRakami: Insulo-acinar axis, its vascular basis and its functional and morphological changes caused by CCK-PZ and caerulein. In: (ed. by) T. FujiTA: Endocrine gut and pancreas. Elsevier, Amsterdam, 1976 (p. 347-357).

Hebel, R. and M. W. Stromberg: Circulatory system. In: (ed. by) R. Hebel and M. W. STRomberG: Anatomy of laboratory rat. The Williams and Wilkins, Baltimore, 1976 (p. 91-111).

Henderson, J. R.: The role of the islets of Langerhans in exocrine function of the pancreas. In: (ed. by) A. KoO, S. K. LAM and L. H. SMAJE: Microcirculation of the alimentary tract. World Scientific, Singapore, 1983 (p. 235-239).

Henderson, J. R., P. M. Daniel and P. A. Frazor: The pancreas as single organ: the influence of the endocrine upon the exocrine part of the gland. Gut 22: 158-167 (1981).

Lifson, N. and C. V. Lassa : Note on the blood supply of the ducts of the rabbit pancreas. Microvasc. Res. 22: 171-176 (1981).

McCuskey, R. S. and T. M. Chapman: Microscopy of the living pancreas in situ. Amer. J. Anat. 126: 395-408 (1969).

MCDonald, D. M. and D. T. LARUE: The ultrastructure and connections of blood vessels supplying the rat carotid body and carotid sinus. J. Neurocytol. 12: 117153 (1983).

Miyake, T., T. Murakami and A. Ohtsuka: Incomplete vascular casting for a scanning electron microscope study of the microcirculatory patterns in the rat pancreas. Arch. Histol. Cytol. 55: 397-406 (1992).

Murakami, T.: Application of the scanning electron microscope to the study of the fine distribution of the blood vessels. Arch. Histol. Jap. 32: 445-454 (1971).

Murakami, T., M. Unehara, H. KaWaKami and A. Kubotsu: Osmium impregnation of methyl methacrylate vascular casts for scanning electron microscopy. Arch. Histol. Jap. 36: 119-124 (1973).

Murakami, T., T. Fujita, T. Taguchi, Y. Nonaka and K. ORITA: The blood vascular bed of the human pancreas, with special reference to the insulo-acinar portal system. Scanning electron microscopy of corrosion casts. Arch. Histol. Cytol. 55: 381-395 (1992).

Murakami, T., T. Taguchi, A. Ohtsuka, K. Sano, T. KAneshige, R. L. Owen and A. L. Jones: A modified method of fine-granular cationic iron colloid preparation: its use in the rat kidney glomerulus and certain other tissues. Arch. Histol. Jap. 49: 13-23 (1986).

Ohtani, 0.: Microcirculation of the pancreas: a correlative study of intravital microscopy with scanning electron microscopy of vascular corrosion casts. Arch. Histol. Jap. 46: 315-325 (1983).
Ohtani, O.: Microcirculation in the pancreas (In Japanese). Igaku no Ayumi 144: 344-347 (1988).

Ohtani, O. and T. Fujita: Insulo-acinar portal system of the pancreas. A scanning electron microscope study of corrosion casts. In: (ed. by) E. A. VIDRIO and M. A. GalinA: Advance in the morphology of cells and tissues (Progr. Clin. Biol. Res., Vol. 59B). Alan R. Liss, New York, 1981 (p.111-120).

Ohtani, O., T. Ushiki, H. Kanazawa and T. Fujita: Microcirculation of the pancreas in the rat and rabbit with special reference to the insulo-acinar portal system and emissary vein of islet. Arch. Histol. Jap. 49: 4560 (1986).

Syed ALI, S.: Angioarchitecture of the pancreas of the cat. Light- scanning- and transmission electron microscopy. Cell Tiss. Res. 235: 675-682 (1984).

Syed Ali, S., M. M. Syed Ali, M. A. Hafeez and M. M. AнmAD: Microangioarchitecture of the islets of Langerhans in the snakes, Naja naja, Vipera russelli, and Echis carinatus. Cell Tiss. Res. 266: 83-88 (1991).

TAGUCHI, T.: Blood vascular organization of the rat carotid body: a scanning electron microscope study of corrosion casts. Arch. Histol. Jap. 49: 243-254 (1986).

Taguchi, T., T. Murakami and A. OHTsuka: Vasculature of the carotid body as observed by scanning electron microscopy of vascular casts. In: (ed. by). P. M. MotTA, T. MuRAKAmi and H. FujITA: Scanning electron microscopy of vascular casts: methods and applications. Kluwer Academic Publishers, Boston-Dordrecht-London, 1992 (p. 199-204).

THiEL, A.: Untersuchungen über das Gefäß-system des Pankreasläppchens bei verschiedenen Säugern mit besonderer Berücksichtigung der Kapillarknäuel der Langerhansschen Inseln. Z. Zellforsch. 39: 339-372 (1954).

Trimble, E. R., R. Bruzzone, A. GJinovel and A. E. RENOLD: Activity of the insulo-acinar axis in the isolated perfused rat pancreas. Endocrinology 117: 12461252 (1985).

WhaRTon, G. K.: The blood supply of the pancreas, with special reference to that of the islands of Langerhans. Anat. Rec. 53: 55-81 (1932).

Prof. Takuro MuRAKAMI Department of Anatomy Okayama University School of Medicine 2-5-1 Shikata-cho, Okayama 700 Japan

村上 宅 郎 700 岡山市鹿田町 2-5-1 岡山大学医学部 第二解剖学教室 